Article

\title{
Quantitative Assessment of Soil Erosion Based on CSLE and the 2010 National Soil Erosion Survey at Regional Scale in Yunnan Province of China
}

\author{
Guokun Chen ${ }^{1,2,3, * \mathbb{D}}$, Zengxiang Zhang ${ }^{1}$, Qiankun Guo ${ }^{3,4,5}$, Xiao Wang ${ }^{1}\left(\mathbb{D}\right.$ and Qingke Wen ${ }^{1,3}$ \\ 1 Renewable Resources Division, Institute of Remote Sensing and Digital Earth, Chinese Academy of Sciences, \\ Beijing 100101, China; zx_zhang@263.net (Z.Z.); wangxiao98@radi.ac.cn (X.W.); wenqk@radi.ac.cn (Q.W.) \\ 2 University of Chinese Academy of Sciences, Beijing 100049, China \\ 3 State Key Laboratory of Earth Surface Processes and Resource Ecology, Beijing Normal University, \\ Beijing 100875, China; guoqiankun@iwhr.com \\ 4 State Key Laboratory of Simulation and Regulation of Water Cycle in River Basins, China Institute of Water \\ Resources and Hydropower Research, Beijing 100048, China \\ 5 Research Center of Soil and Water Conservation of the Ministry of Water Resources, Beijing 100048, China \\ * Correspondence: chengk@radi.ac.cn
}

Received: 6 May 2019; Accepted: 11 June 2019; Published: 12 June 2019

check for updates

\begin{abstract}
Regional soil loss assessment is the critical method of incorporating soil erosion into decision-making associated with land resources management and soil conservation planning. However, data availability has limited its application for mountainous areas. To obtain a clear understanding of soil erosion in Yunnan, a pixel-based estimation was employed to quantify soil erosion rate and the benefits of soil conservation measures based on Chinese Soil Loss Equation (CSLE) and data collected in the national soil erosion survey. Results showed that $38.77 \%$ of the land was being eroded at an erosion rate higher than the soil loss tolerance, the average soil erosion rate was found to be $12.46 \mathrm{t} \cdot \mathrm{ha}^{-1} \cdot \mathrm{yr}^{-1}$, resulting in a total soil loss of $0.47 \mathrm{Gt}$ annually. Higher erosion rates mostly occurred in the downstream areas of the major rivers as compared to upstream areas, especially for the southwest agricultural regions. Rain-fed cropland suffered the most severe soil erosion, with a mean erosion rate of $47.69 \mathrm{t} \cdot \mathrm{ha}^{-1} \cdot \mathrm{yr}^{-1}$ and an erosion ratio of $64.24 \%$. Lands with a permanent cover (forest, shrub, and grassland) were mostly characterized by erosion rates an order of magnitude lower than those from rain-fed cropland, except for erosion from sparse woods, which was noticeable and should not be underestimated. Soil loss from arable land, woodland and grassland accounted for $52.24 \%, 35.65 \%$ and $11.71 \%$ of the total soil loss, respectively. We also found significant regional differences in erosion rates and a close relationship between erosion and soil conservation measures adopted. The CSLE estimates did not compare well with qualitative estimates from the National Soil Erosion Database of China (NSED-C) and only $47.77 \%$ of the territory fell within the same erosion intensity for the two approaches. However, the CSLE estimates were consistent with the results from a national survey and local assessments under experimental plots. By advocating of soil conservation measures and converting slope cropland into grass/forest and terraced field, policy interventions during 2006-2010 have reduced soil erosion on rain-fed cropland by $20 \%$ in soil erosion rate and $32 \%$ in total soil loss compared to the local assessments. The quantitative CSLE method provides a reliable estimation, due to the consideration of erosion control measures and is potentially transferable to other mountainous areas as a robust approach for rapid assessment of sheet and rill erosion.
\end{abstract}

Keywords: spatial quantification; regional soil loss assessment; sampling survey; CSLE; soil conservation measures 


\section{Introduction}

Soil erosion is regarded as one of the most serious and widespread forms of soil degradation, and as such, poses a severe threat to the sustainability and productive capacity of agriculture and terrestrial ecosystems [1-3]. During the last 40 years, nearly one-third of the world's cultivated land has been lost, due to soil erosion, with loss continuing at a rate of more than 10 million hectares per year [4]. Apart from causing on-site impacts, such as reduced soil fertility and productivity, thinner plow layer and poor water holding capacity, the transport of sediments can easily degrade streams, lakes and estuaries, which leads to increased flood risk, reduced lifetime of reservoirs and destruction of habitats [5-7]. Considering the slow soil formation rates, the soil has become a nonrenewable resource to some extent and difficult to reclaim when eroded [8]. In the last few decades, the importance of protecting and restoring the soil resources from erosion has been increasingly recognized by scientists and policymakers around the world.

In order to monitor and assess the environmental and social impacts of soil erosion and to make management strategies to deal with them, quantitative information on soil erosion rates at a regional scale is needed [6,9]. Additionally, formulation of suitable remediation measures, allocation of scarce soil conservation resources and development of policies and regulations also require a clear understanding of the distribution characteristics of erosion at a regional scale to avoid waste $[10,11]$. Therefore, quantitative soil erosion assessment at a regional scale for sustainable agriculture and environment is essential.

Although a wide variety of approaches have been employed to assess soil erosion caused by water in different regions around the world. For a long time, quantitative studies have been focused on the scales of plot size, hill-slope and catchment. Methods applied at small scales, such as direct observation, erosion tracer methods, sediment concentration measurement mostly become impractical, due to the large temporal and spatial variability of soil erosion affecting factors [12]. The demand for credible information on regional-scale erosion and the environment has led to the development of many monitoring efforts, inventory programs, and inter-agency cooperation for erosion assessment data collection. Along with these efforts devoted, methods of regional scale soil erosion assessment also developed [13-15].

At present, the general approaches to regional soil loss assessment can be divided into several categories [14]. The first category includes an assessment based on a sample survey and distributed point/area data. The well-known example of sample survey is the National Resource Inventory (NRI) conducted by the US Department of Agriculture's Natural Resources Conservation Service (NRCS) for decades [16], which employs Universal Soil Loss Equation (USLE) and its revised version RUSLE [17,18] to estimate long-term averages of sheet and rill erosion. Others focused on the extrapolation of data from experimental runoff plot and field-based measurements to regional scale. For example, Cerdan et al. (2010) extrapolated measured data from erosion plots under natural rainfall and revealed that the mean rill and inter-rill erosion rates are $1.2 \mathrm{tha}^{-1} \mathrm{yr}^{-1}$ for the whole CORINE area and $3.6 \mathrm{tha}^{-1} \mathrm{yr}^{-1}$ for arable land in Europe [19]. Based on runoff plot data, Guo et al. (2015) analyzed the soil loss rate range for the five water erosion regions in China and reported values of 30.87-107.44 $\mathrm{t} \cdot \mathrm{ha}^{-1} \cdot \mathrm{yr}^{-1}$ on fallow land and 7.65-49.38 t.ha ${ }^{-1} \cdot \mathrm{yr}^{-1}$ on farmland [20]. Evans et al. (2016) extrapolated field-based data across the landscape and clarified the extent and frequency of water erosion rate from arable land in Britain [21]. Xie et al. (2019) quantified soil erosion changes in cropland in northeastern China over the past 300 years using data form field survey and historical cropland areas [22]. However, it is important to note that the direct extrapolation may cause poor estimation of regional soil erosion rates if the scale issue is not carefully considered [19]. The second category includes qualitative methods of factorial approaches and expert-based methods. A representative example is the national soil erosion remote sensing investigations conducted in China. By using the Landsat TM data and 1:50,000 relief map, a man-computer interactive interpretation was employed to determine soil erosion intensity based on performance in slope and vegetation cover [23]. Other studies include soil erosion risk assessment using the GLASOD method [24] and the CORINE approach [25]. The third category 
includes model-based grid estimation of empirical, physical and distributed models. The typical example is soil erosion risk assessment in Europe based on various methods, such as the PESERA method [26], the EUROSEM method [27] and the recent assessments using the EIONET network [28]. By using a modified version of RUSLE, Panagos et al. (2015) reported that the mean soil loss rate and total soil loss from European Union's erosion-prone lands were $2.46 \mathrm{t} \mathrm{ha}^{-1} \mathrm{yr}^{-1}$ and $970 \mathrm{Mt}$ [29]. Karamage et al. (2016) assessed the soil erosion rate of Rwanda using RUSLE and Landsat OLI data and found that cropland erosion was responsible for approximately $95 \%$ of the country's soil loss [30]. De Vente et al. (2008) quantified soil erosion and sediment yield at regional scales in Spain using three distributed models of WATEM-SEDEM model, the PESERA model and SPADS [13]. However, for application at the regional scale, most erosion models are severely limited by their high data demand [15]. Each of these categories has its own advantages and disadvantages, sampling survey and runoff plot data provide the most detailed information on erosion, but requires a lot of field work, model based-grid estimation and qualitative methods usually provide a full-coverage evaluation, but rarely take the soil conservation measures into consideration, due to the spatial resolution limitations, thereby the results are usually expressed as soil erosion risk, which cannot provide precise soil loss rates and reflect the benefits of soil conservation measures. In general, the availability and quality of input data is probably the most important consideration when selecting an assessing method at a regional scale [25].

In 2010 through 2012, by using unequal probability sampling methods and the Chinese Soil Loss Equation (CSLE) model, the Ministry of Water Resources of China (MWRC) conducted the fourth national soil erosion survey [14,23,31], known as the 2010 NSES. Different from the previous three qualitative soil erosion surveys using satellite imagery, this is the first ever national survey to incorporate sampling survey, field investigation, model-based calculation and latest spatial information techniques in China's history to quantify soil erosion. Sampling investigation is the main method of the survey. According to the erosion types involved and actual situations of each province in China, a total of 33,966 primary sample units (PSUs) were determined and allocated in the field with sampling densities of $4 \%, 1 \%, 0.25 \%$ and $0.0625 \%$. Each PSU is a $1 \mathrm{~km} \times 1 \mathrm{~km}$ grid in the plain area or a small watershed with area from 0.2 to $3.0 \mathrm{~km}^{2}$ in the mountainous area, which was selected for investigation [32]. Thousands of data gathered in the country were instructed to visit every land parcel (defined as land with same land use and conservation practice) in each PSU and collect indicators of soil erosion in the field. The data collected concerning the erosion affecting factors share uniform standards and specifications and was well-examined in every step of the survey. After a comprehensive analysis of rainfall, soil, terrain, land use and soil conservation practice, the soil erosion rate was computed by CSLE model with a spatial resolution of $10 \mathrm{~m}$ for each land parcel, then statistical methods were applied to evaluate the distribution, area and intensity of soil erosion at PSU, county, provincial and national levels [22]. Yunnan, as one of the mountainous provinces suffering from severe soil erosion, received a lot of attention in the national survey for its complex erosion conditions and irreplaceable ecological value. Little published work is available of soil erosion rates or soil conservation measures in Yunnan so far, due to the steep topographic conditions, complex crop rotation system and various soil conservation measures.

The objectives of this paper are: (a) To quantify soil erosion by water in Yunnan using CSLE and available PSUs data in the 2010 NSES; (b) to study soil erosion variations and regional differences under different land use types in Yunnan; (c) to compare the CSLE method with the traditional qualitative RS approach, the comparison aims to clarify the advantages and disadvantages of the methods and thereby contribute to the rational selection of the suitable methods for regional soil erosion assessment; (d) and to analyze the effectiveness of policy interventions on soil erosion reduction by comparing the results to previous local studies. 


\section{Materials and Methods}

\subsection{Study Area}

Yunnan Province is situated in the extreme southwest of China, and lies between $21^{\circ} 09^{\prime}-29^{\circ} 15^{\prime} \mathrm{N}$ and $97^{\circ} 32^{\prime}-106^{\circ} 12^{\prime} \mathrm{E}$ (Figure 1 ). The province covers an area of more than $3.83 \times 10^{5} \mathrm{~km}^{2}$, bordering the Himalayas and Myanmar in the west, Vietnam and Laos in the south. Altitude in Yunnan varies considerably, from less than $100 \mathrm{~m}$ of the Red River at the southeast edge to more than $6700 \mathrm{~m}$ in the northwest mountainous areas, with an average value of approximately $2000 \mathrm{~m}$. High mountains and deep valleys characterize the western parts, whereas in eastern Yunnan, rivers generally flow in relatively shallow valleys, forming a landscape tilting from the northwest to the southeast. Affected by monsoons and the west-wind circulation, the climate is typical sub-tropical monsoonal, though relatively mild, due to the high altitude [33]. Precipitation is abundant, but unevenly distributed in time and space, ranging from less than $600 \mathrm{~mm}$ in dry valleys to more than $2000 \mathrm{~mm}$ in the southern mountainous areas, with a mean value of $1100 \mathrm{~mm}$. About $85 \%$ of the annual precipitation is concentrated in the months from May to October [34]. The major soil groups (FAO/UNESCO classifications) in the province are: Acrisols (34.44\%) that mainly distributed in southern Yunnan, Cambisols $(25.12 \%)$ that mainly distributed in the central portion, Luvisols $(22.44 \%)$ that mostly distributed in the northwest, Alisols (7.36\%) that mainly distributed in the tips of southwest, southeast and northeast, and Anthrosols (4.39\%) that dispersed in the whole province (Figure 2b). Both Acrisols and Alisols are rich in clay and formed under great precipitation and high temperature conditions, while Luvisols is characterized as a kind of soil that clay has been leached after snowmelt or heavy rains. Cambisols are generally developed in medium and fine-textured materials. Rice, wheat and maize are the principle food crops grown, while tea, sugar cane, tobacco and rubber are the main cash crops. The topographical variety also contributes to a vast territory with diversified and unique natural resources. Spinning only $8^{\circ}$ in latitude, the province holds all the land ecosystems that can be found in the $35^{\circ}$ range of latitudes of the country [35]. Six major rivers flow through the province, among which the Irrawaddy, the Salween, the Mekong and the Yangtze originate from the Qinghai-Tibet plateau. Two other rivers, the Red and the Pearl originate from the province itself. The population of Yunnan in 2010 was 46 million (National Bureau of Statistics of China, 2010). With some $84 \%$ of the province classed as mountains and the plain areas already fully utilized for agriculture, pressure on remaining land resources is high.

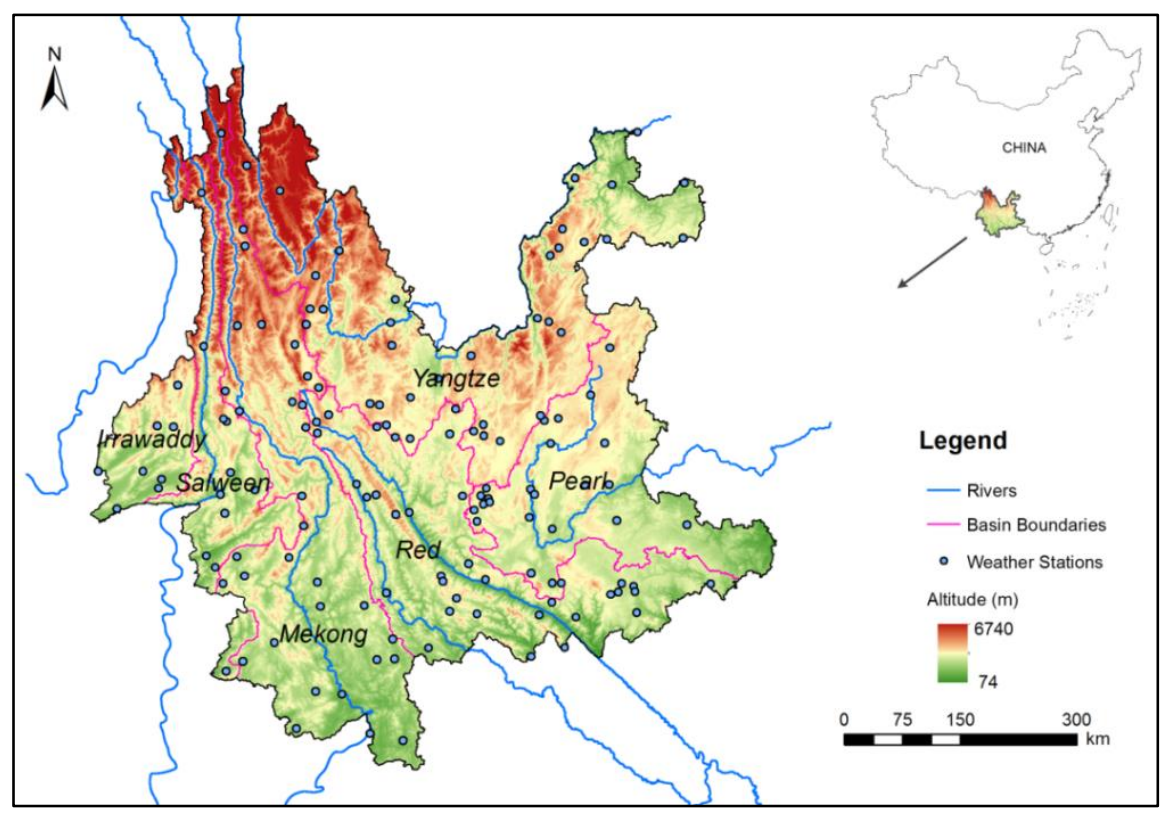

Figure 1. Map of Yunnan showing major rivers, basins, weather stations and altitude variation. 


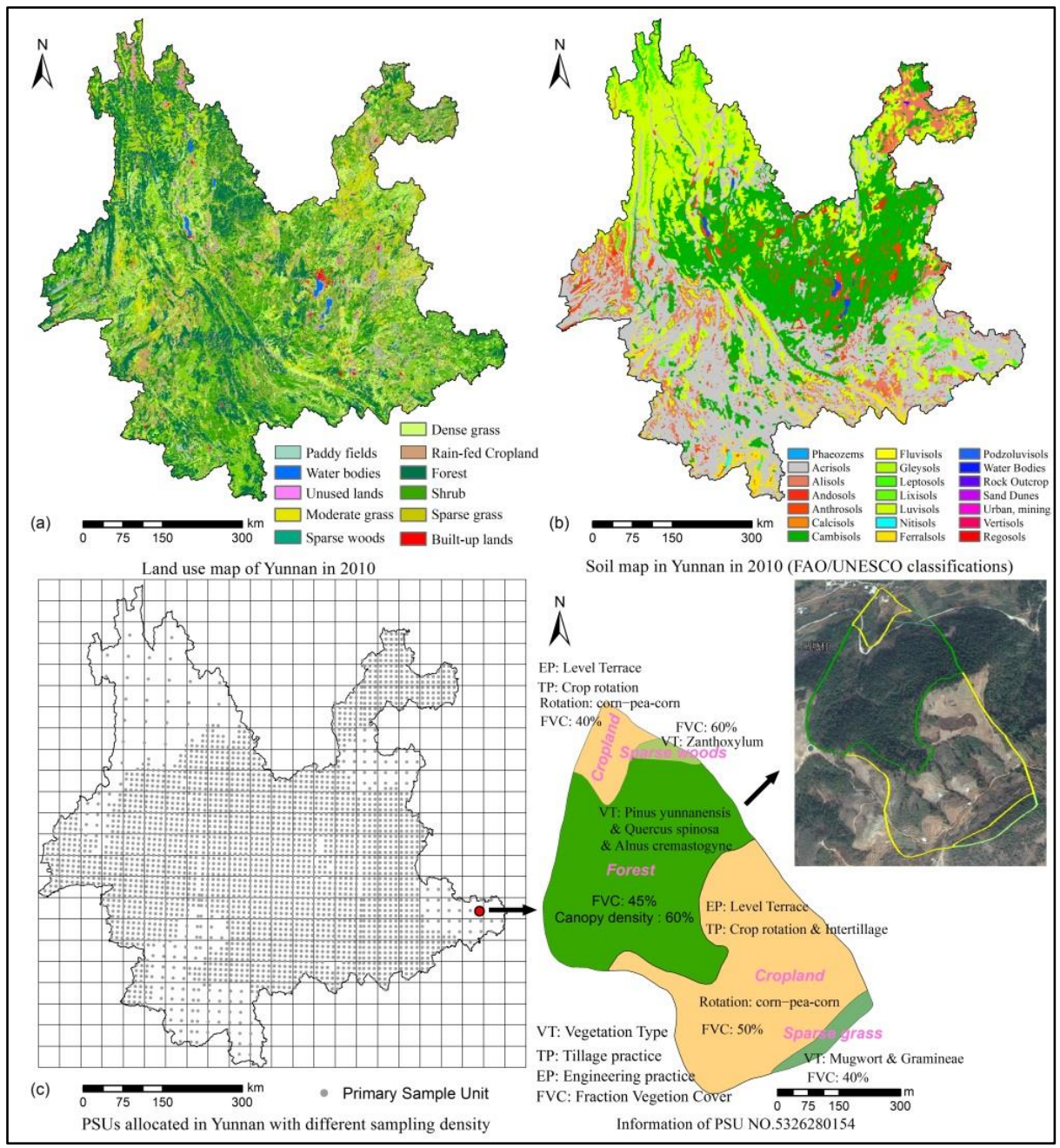

Figure 2. Maps of Yunnan showing: (a) Land use types; (b) Soil groups; (c) Primary sample units (PSUs) allocated in the National Soil Erosion Survey; (d) an detailed PSU example.

\subsection{Data Sources}

The major factors that determine the magnitude of soil erosion rate are rainfall, the nature of the soil, vegetation cover, the tillage practices used and mechanical farming measures, such as terracing and contouring [7]. Critical data concerning these factors in the study were obtained as follows:

Daily erosive rainfall ( $\geq 12 \mathrm{~mm}$ ) data from 143 meteorological stations in Yunnan for three decades (1981-2010), provided by the National Meteorological Data Sharing Service System (http://data.cma.cn), was used to develop an average annual rainfall erosivity map. Soil maps retrieved from the Second National Soil Survey (http://westdc.westgis.ac.cn) were used to develop a soil erodibility map. ASTER GDEM datasets (http://www.usgs.gov) at a spatial resolution of $30 \mathrm{~m}$ were prepared to derive topographical parameters. The remote sensing data used to calculate the vegetation cover consists of three aspects. The $250 \mathrm{~m}$ MODIS NDVI data, the $30 \mathrm{~m} \mathrm{HJ}$ multi-spectral reflectance data (http: //www.cresda.com) and a land use map. The land use datasets of Yunnan in 2010 (Figure 2a) was retrieved from the National Land Use/Cover Database of China (NLUD-C) at the scale of 1:100,000, developed by CAS. NLUD-C was derived from the Landsat TM/ETM data at a spatial resolution of $30 \mathrm{~m}$ and used for the land use/cover related assessment as it is the most well-known land use classification in China. The database includes seven datasets of land use status of China in the 1980s, 1995, 2000, 2005, 2008, 2010 and 2015, along with six corresponding datasets describes land use change information during these periods. Land use types are classified into six first-level types (arable land, woodland, grassland, water bodies, built-up land and unused land) and 25 corresponding second-level 
types [36]. Woodland is the most dominant land use type in 2010, which accounts for $57.64 \%$ of the province, grassland accounts for $22.55 \%$, arable land covers $17.80 \%$ of the area, unused land, built-up land and water bodies take up $2.01 \%$. Figure 2c shows the 2871 primary sample units (PSUs) allocated in Yunnan from the 2010 National Soil Erosion Survey, which were provided by Beijing Normal University (Technical support unit of the national survey) and integrated into land use datasets to generate raster layers of soil conservation measures. Figure $2 \mathrm{~d}$ shows a specific PSU in the field and information for each land parcel within the PSU.

All these data were converted to a $30 \mathrm{~m}$ spatial resolution before incorporated as input layers in the CSLE model for further analysis.

\subsection{Quantitative Pixel-Based Estimation Using CSLE Model and PSUs Data}

By adapting parameters of USLE to the target areas, many Chinese scholars have proposed some regional soil loss prediction models for soil loss estimation and soil conservation planning since the 1980s. In 2002, Liu et al. [37] developed the Chinese Soil Loss Equation (CSLE) model based on measured data from Chinese unit plot and numerous plots modified to Chinese unit plot. CSLE is a statistical relationship model that correlates soil loss rates and the affecting factors, which can be modified according to the local conditions and has been widely verified and applied in China. The CSLE formula is defined as follows:

$$
A=R \times K \times L \times S \times B \times E \times T,
$$

where $A$ is the average annual soil loss, $\mathrm{t}^{\mathrm{ha}} \mathrm{a}^{-1} \cdot \mathrm{yr}^{-1} ; R$ is the average annual rainfall erosivity, $\mathrm{MJ} \cdot \mathrm{mm} \cdot \mathrm{ha}^{-1} \cdot \mathrm{h}^{-1} \cdot \mathrm{yr}^{-1} ; K$ is the soil erodibility, tha $\cdot \mathrm{h} \cdot \mathrm{ha}^{-1} \cdot \mathrm{MJ}^{-1} \cdot \mathrm{mm}^{-1} ; L$ is the slope length factor and $S$ is the slope steepness factor; $B, E, T$ are the erosion-control practices of biological, engineering and tillage, respectively. The factors of topography and soil conservation measures are dimensionless.

\subsubsection{Rainfall Erosivity (R-Factor)}

The erosive force of rainfall and consequent runoff is referred to as rainfall erosivity or the $R$-factor. It reflects the potential ability of rainfall to cause erosion and has been widely used for empirical soil loss estimation for the past several decades. Its calculation, however, requires high temporal resolution hyetograph data that is rarely available at standard meteorological stations in many parts of the world [38,39]. Due to the limited availability, alternative approaches based on more commonly available data, such as daily, monthly, and annual rainfall data have been used. In this study, daily erosive rainfall data of three decades from 133 meteorological stations in Yunnan were used to estimate the R-factor using the Cold-Warm Season Daily Rainfall Model [40] in the national survey. The formula is expressed as:

$$
\begin{gathered}
R=\sum_{k=1}^{24} R_{k}, \\
R_{k}=\frac{1}{N} \sum_{i=1}^{N} \sum_{j=0}^{m}\left(\alpha \cdot P_{i, j, k}^{1.7265}\right), \\
W R_{k}=\frac{R_{k}}{R},
\end{gathered}
$$

where $R$ is the average annual rainfall erosivity (MJ.mm $\left.\cdot h a^{-1} \cdot \mathrm{h}^{-1} \cdot \mathrm{a}^{-1}\right), k$ represents the 24 half months in a year, $R_{k}$ is the average rainfall erosivity in the $k$-th half month (MJ.mm $\cdot \mathrm{ha}^{-1} \cdot \mathrm{h}^{-1} \cdot \mathrm{a}^{-1}$ ), $N$ refers to the time series from 1981 to 2010, the term $\alpha$ is a value of 0.3937 for warm season (May to September) and 0.3101 for cold season (October to April), $P_{i, j, k}$ is the actual erosive rainfall $(\geq 12 \mathrm{~mm}$ ) of the $j$-th day in the $k$-th half month in the $i$-th year, $m$ is the number of days with erosive rainfall in the corresponding half month. $W R_{k}$ is the ratio of average rainfall erosivity in the $k$-th half month to the average annual rainfall erosivity, which reflects the seasonal distribution of rainfall erosivity. For each 
station, the R-factor was estimated for the period during 1981-2010 and Kriging was applied as the method of spatial interpolation to create an erosivity map.

\subsubsection{Soil Erodibility (K-Factor)}

Soil erodibility represents soil's susceptibility to being detached and transported by the actions of raindrops and runoff [41]. In USLE, it was defined as the average soil loss rate per unit of rainfall erosivity index from a cultivated continuous fallow plot, with a $22.1 \mathrm{~m}$ long $9 \%$ slope [42]. The K-factor was determined using the USLE equations [43] based on national soil survey data, and then adjusted using measured unit plot data and cropland plot data. The equations are:

$$
\begin{gathered}
K=\left[2.1 \times 10^{-4} M^{1.14}(12-O M)+3.25(S-2)+2.5(P-3)\right] / 100, \\
M=N_{1}\left(100-N_{2}\right), \\
M=N_{1}\left(N_{3}+N_{4}\right),
\end{gathered}
$$

where $K$ is soil erodibility, $N_{1}$ (particle size $\left.0.002-0.1 \mathrm{~mm}\right)$ is the percent of silt $(0.002-0.05 \mathrm{~mm}$ ) plus very fine sand $(0.05-0.1 \mathrm{~mm}), N_{2}(<0.002 \mathrm{~mm})$ is the clay fraction, $\left(100-N_{2}\right)(0.002-2 \mathrm{~mm})$ represents all soil fractions other than clay, $O M$ is the soil organic matter content $(\%), S$ is the soil structure code, and $P$ is the soil permeability code.

\subsubsection{Topographic Factors (LS-Factors)}

Topographic factors include slope steepness factor and slope length factor. In the present study, a DEM-based procedure developed by Fu et al. [44] was employed to generate CSLE-based raster layers of LS-factors. The algorithms used in the procedure integrated the raster grid accumulation with maximum downhill slope methods similar to that proposed by Hickey [45]. The DEM datasets were derived from ASTER GDEM. The segment slope length equation proposed by Foster [46] was employed to calculate the L-factor, and S-factor follows the USLE equation for gentle slopes while a modification is made for steep slope conditions based on measured data [47].

$$
\begin{gathered}
S= \begin{cases}10.8 \sin \theta+0.03 & \theta \leq 5^{\circ} \\
16 \sin \theta-0.50 & 5^{\circ}<\theta \leq 10^{\circ}, \\
21.9 \sin \theta-0.96 & \theta>10^{\circ}\end{cases} \\
L_{i}=\frac{\left(\lambda_{\text {out }}^{m+1}-\lambda_{\text {in }}^{m-1}\right)}{\left[\left(\lambda_{\text {out }}-\lambda_{\text {in }}\right) \times 22.13^{m}\right]}\left\{\begin{array}{ll}
m=0.2 & \theta \leq 1^{\circ} \\
m=0.3 & 1^{\circ}<\theta \leq 3^{\circ} \\
m=0.4 & 3^{\circ}<\theta \leq 5^{\circ} \\
m=0.5 & \theta>5^{\circ}
\end{array},\right.
\end{gathered}
$$

where $L i$ is the slope length factor of the $i$-th pixel, $\lambda_{\text {out }}, \lambda_{\text {in }}$ are the pixel exit and entrance slope lengths, and $m$ is the slope length exponent depending on the slope.

\subsubsection{Soil Conservation Practices (BET-Factors)}

During the development of the historical agriculture traditions in China, the systematical measures for soil conservation formed. The major difference between CSLE and USLE is that soil conservation practice factors of crop management ( $C$-factor) and erosion-control ( $P$-factor) used in the USLE are described by three erosion-control factors of biological (B-factor), engineering ( $E$-factor) and tillage (T-factor) according to Chinese soil and water conservation classifications [48]. In the 2010 NSES, investigation of these erosion control measures in PSUs was the major task and all the relevant attributes of these measures were obtained and recorded in the field. 


\section{Biological Practice (B-Factor)}

The role of vegetation cover on preventing soil erosion is well recognized. To account for vegetation, a biological control practices factor ( $B$-factor) has been used in erosion assessments in the CSLE. The $B$-factor only refer to the forest or grass plantation for reducing runoff and soil loss, vegetation cover for arable lands are not included. Similar to $C$-factor in USLE, $B$ values are weighted average soil loss ratios $\left(B_{i}\right)$, each of which represents the ratio of soil loss under current conditions of a certain period of time to the soil loss under unit plot conditions during the same period [49]. $B_{i}$ changes as vegetation cover changes during the process of plant growth. The $B$ value then represents the average of $B_{i}$ values, each weighted by the portion of rainfall erosivity during the same time period.

In this study, the B-factor layer was acquired as follows: First, vegetation coverage fraction (FVC) of 24 half months across the year for different vegetation types were calculated based on NDVI derived from time series of remote sensing images and field survey. Land use classification was then used to obtain $B$ values. For arable land, built-up land, water areas and unused land, $B$ values were assigned directly based reported value in literature. For woodland and grassland, $B$ value for each half-month period was calculated across the year, and the ratio of the corresponding half-month $R_{i}$ value to annual $R$ was used as the weight to calculate the annual average $B$-factor value. The $F V C$ and $B$-factor are calculated using NDVI as follows:

$$
\begin{gathered}
F V C=\frac{\left(N D V I-N D V I_{\text {soil }}\right)}{\left(N D V I_{\text {veg }}-N D V I_{\text {soil }}\right)}, \\
B=\frac{\sum_{i=1}^{24} B_{i} R_{i}}{\sum_{i=1}^{24} R_{i}},
\end{gathered}
$$

where $F V C$ is vegetation coverage fraction; $N D V I_{\max }$ refers to the regional maximum NDVI; $N D V I_{\text {veg }}$ is the NDVI value of the pure vegetation pixels; $N D V I_{\text {soil }}$ is NDVI value of the pure bare soil pixels; $R_{i}$ is the rainfall erosivity portion for the $i$-th half month; $B_{i}$ is the $B$-factor of the $i$-th half month. The relationship between vegetation coverage fraction $(F V C)$ and $B$ value was compiled in Table 1 , which was summarized in the 2010 NSES according to the literature [50].

Table 1. $B$ values for grassland, shrub and woodland of different vegetation coverage fractions.

\begin{tabular}{cccccccccccccc}
\hline \multirow{2}{*}{ FVC (\%) } & Grassland & Shrub & \multicolumn{1}{c}{ Woodland Canopy Density (\%) } \\
\cline { 5 - 13 } & & & $\mathbf{1 0}$ & $\mathbf{2 0}$ & $\mathbf{3 0}$ & $\mathbf{4 0}$ & $\mathbf{5 0}$ & $\mathbf{6 0}$ & $\mathbf{7 0}$ & $\mathbf{8 0}$ & $\mathbf{9 0}$ & $\mathbf{1 0 0}$ \\
\hline $\mathbf{0}$ & 0.516 & 0.614 & 0.438 & 0.426 & 0.414 & 0.402 & 0.390 & 0.378 & 0.366 & 0.354 & 0.342 & 0.330 \\
$\mathbf{1 0}$ & 0.345 & 0.310 & 0.317 & 0.309 & 0.301 & 0.293 & 0.285 & 0.276 & 0.268 & 0.260 & 0.252 & 0.244 \\
$\mathbf{2 0}$ & 0.242 & 0.200 & 0.196 & 0.192 & 0.187 & 0.183 & 0.179 & 0.175 & 0.171 & 0.166 & 0.162 & 0.158 \\
$\mathbf{3 0}$ & 0.017 & 0.150 & 0.149 & 0.146 & 0.143 & 0.140 & 0.137 & 0.134 & 0.131 & 0.128 & 0.125 & 0.122 \\
$\mathbf{4 0}$ & 0.110 & 0.105 & 0.102 & 0.100 & 0.098 & 0.096 & 0.095 & 0.093 & 0.091 & 0.089 & 0.087 & 0.085 \\
$\mathbf{5 0}$ & 0.073 & 0.065 & 0.072 & 0.071 & 0.070 & 0.068 & 0.067 & 0.066 & 0.065 & 0.064 & 0.063 & 0.062 \\
$\mathbf{6 0}$ & 0.042 & 0.040 & 0.042 & 0.041 & 0.041 & 0.040 & 0.040 & 0.040 & 0.039 & 0.039 & 0.038 & 0.038 \\
$\mathbf{7 0}$ & 0.028 & 0.027 & 0.027 & 0.027 & 0.027 & 0.027 & 0.026 & 0.026 & 0.026 & 0.026 & 0.025 & 0.025 \\
$\mathbf{8 0}$ & 0.013 & 0.013 & 0.013 & 0.013 & 0.013 & 0.013 & 0.013 & 0.013 & 0.012 & 0.012 & 0.012 & 0.012 \\
$\mathbf{9 0}$ & 0.006 & 0.006 & 0.006 & 0.006 & 0.006 & 0.006 & 0.006 & 0.006 & 0.006 & 0.006 & 0.006 & 0.006 \\
$\mathbf{1 0 0}$ & 0.003 & 0.003 & 0.003 & 0.003 & 0.003 & 0.003 & 0.003 & 0.003 & 0.003 & 0.003 & 0.003 & 0.003 \\
\hline
\end{tabular}

Engineering and Tillage Practices (ET-Factors)

In USLE, $P$-factor was defined as the ratio of soil loss with the practice applied to up-and-downslope cultivation. In CSLE, it is described as the engineering control measures $(E)$ and tillage control measures (T) factors. Engineering measures refer to the changes of topography to reduce runoff and soil loss by engineering construction. Tillage measures refer to the measures taken by farmland equipment, such as the ways to improve soil resistance to erosion, and reduce erosion by increasing surface cover 
or increasing soil infiltration to achieve conservation purpose. The difference between them is that the latter does not change the topography and are only applied on the cropland [37]. Both E-factor and $T$-factor has a dimensionless range of $0-1$. The smaller the value is, the better the soil conservation benefit of a certain measure is.

Of the six input factors in USLE, values of the P-factor are considered as the most uncertain and rarely taken into account in conventional soil erosion models as it is difficult to estimate [51]. Most studies estimate the P-factor values according to land use types or slope. In the 2010 NSES, through a large amount of literature and investigation, the preliminary crop rotation factors of ten crops in China were established [49]. T-factor values of 376 rotation systems were obtained and E-factor values of 112 categories were compiled [32,50]. For Yunnan Province, a total of 20,156 land parcels in the 2871 PSUs were visited. Attributes (type, area, area percentage, quantity, crop rotation system, vegetative coverage) of erosion control measures in all these land parcels were identified, measured and recorded and then assigned from reported values in literature and measured natural runoff plots data.

In this study, we integrated all these PSUs data with land use map to generate raster layers of soil conservation measures. Take T-factor of farmland as an example, first we figured out all types of tillage measures adopted in farmland parcels in a PSU, then an area weighted average method was employed based on reported values of these measures and their attributes (types, corresponding $T$ values and area percentage) to calculate the mean $T$ value for farmland in this PSU, finally, mean $T$ values of all farmland PSUs were interpolated using the nearest neighbor interpolation method to generate the $T$-factor raster layer of farmland in the province. According to the field survey, the $E-T$ measures that most commonly occurred in Yunnan and their corresponding E-T values were compiled in Table 2. Erosion control measures, such as terracing, contour cropping and film mulching accounted for a large proportion and generated huge impacts on soil erosion reduction.

Table 2. Major $E-T$ measures adopted in Yunnan in the 2010 NSES and their corresponding values.

\begin{tabular}{cccc}
\hline Engineering Measures & $\boldsymbol{E}$-Value & Tillage Measures & $T$-Value \\
\hline Sloping terrace & 0.4 & No-tillage & 0.14 \\
Level terrace & 0.1 & Lea farming & 0.23 \\
Fruit tree pit & 0.1 & Contour cropping & 0.43 \\
Slope protection & 0.2 & Contour cropping and crop rotation & 0.17 \\
Gully head protection & 1.0 & Inter-tillage & 0.50 \\
Intercepting drain & 0.8 & Cross slope intercropping & 0.20 \\
Diversion canal & 1.0 & Ridged-furrow & 0.15 \\
Urban settlement & 0.1 & Crop rotation & $0.37-0.41$ \\
Rural settlement & 0.2 & Rotation and fallow & 0.09 \\
Level trench & 0.3 & Crop rotation and film mulching & 0.20 \\
Plain paddy & 0 & Intercropping and inter-planting & 1.00 \\
Check dam & 0.6 & Lea farming and fallow & 0.05 \\
Slope-separated terrace & 0.2 & Contour furrow planting & 0.18 \\
- & - & Inclined ridging & 0.70 \\
\hline
\end{tabular}

\subsection{Qualitative Assessment of Soil Erosion Intensity}

To compare the results estimated by the above method with estimates from the National Soil Erosion Database of China (NSED-C) based on the national soil erosion remote sensing survey, the same datasets and qualitative integrated evaluation methods were also adopted. By referring to the SL190-2007: Standard for Classification and Gradation of Soil Erosion (Table 3) on the classification of erosion, the study area was divided into six zones with different slope gradient zones and five categories with different vegetation coverage range (Figure 3) to assess the soil erosion intensity in Yunnan in 2010 with assistance of data on soil types and landscape characteristics [12].

For vegetation cover, woodland and grassland showed similar pattern in distribution as the $45-60 \%, 30-45 \%$ and $60-75 \%$ categories were the top three dominant classes, the area percentage for woodland in these classes are $46.52 \%, 31.25 \%$ and $16.03 \%$, and the percentage for grassland are $45.13 \%$, 
$29.91 \%$ and $17.62 \%$, respectively. As can be seen in Figure 3a, woodland and grassland with lower vegetation cover were mainly distributed in the highlands in the northwestern Yunnan. The area with slope $<5^{\circ}$ accounts for $28.60 \%$ of the total land area, slope gradient of $5-8^{\circ}, 8-15^{\circ}, 15-25^{\circ}, 25-35^{\circ}$ and $>35^{\circ}$ representing $7.12 \%, 22.30 \%, 27.54 \%, 11.48 \%$ and $2.97 \%$ of the total land area, respectively.

Table 3. Standards for the classification and gradation of soil erosion intensity levels.

\begin{tabular}{cccccccc}
\hline \multirow{2}{*}{ Land Use Types } & \multirow{2}{*}{$\begin{array}{c}\text { Vegetation } \\
\text { Cover }\end{array}$} & \multicolumn{7}{c}{ Slope Gradient } \\
\cline { 3 - 8 } & $>75 \%$ & Slight & Slight & Slight & Slight & Slight & Slight \\
& $60-75 \%$ & Slight & Light & Light & Light & Moderate & Moderate \\
Non-cultivation & $45-60 \%$ & Slight & Light & Light & Moderate & Moderate & Intensive \\
& $30-45 \%$ & Slight & Light & Moderate & Moderate & Intensive & Severe \\
& $<30 \%$ & Slight & Moderate & Moderate & Intensive & Severe & Extreme \\
Slope-cultivation & - & Slight & Light & Moderate & Intensive & Severe & Extreme \\
\hline
\end{tabular}

Note: Relationships between soil erosion intensities and rates are: Slight $\left(<5 \mathrm{t} \cdot \mathrm{ha}^{-1} \cdot \mathrm{yr}^{-1}\right)$, light $\left(5-25 \mathrm{t} \cdot \mathrm{ha}^{-1} \cdot \mathrm{yr}^{-1}\right)$, moderate $\left(25-50 \mathrm{t} \cdot \mathrm{ha}^{-1} \cdot \mathrm{yr}^{-1}\right)$, intensive $\left(50-80 \mathrm{t} \cdot \mathrm{ha}^{-1} \cdot \mathrm{yr}^{-1}\right)$, severe $\left(80-150 \mathrm{t} \cdot \mathrm{ha}^{-1} \cdot \mathrm{yr}^{-1}\right)$ and extreme $\left(>150 \mathrm{t} \cdot \mathrm{ha}^{-1} \cdot \mathrm{yr}^{-1}\right)$.

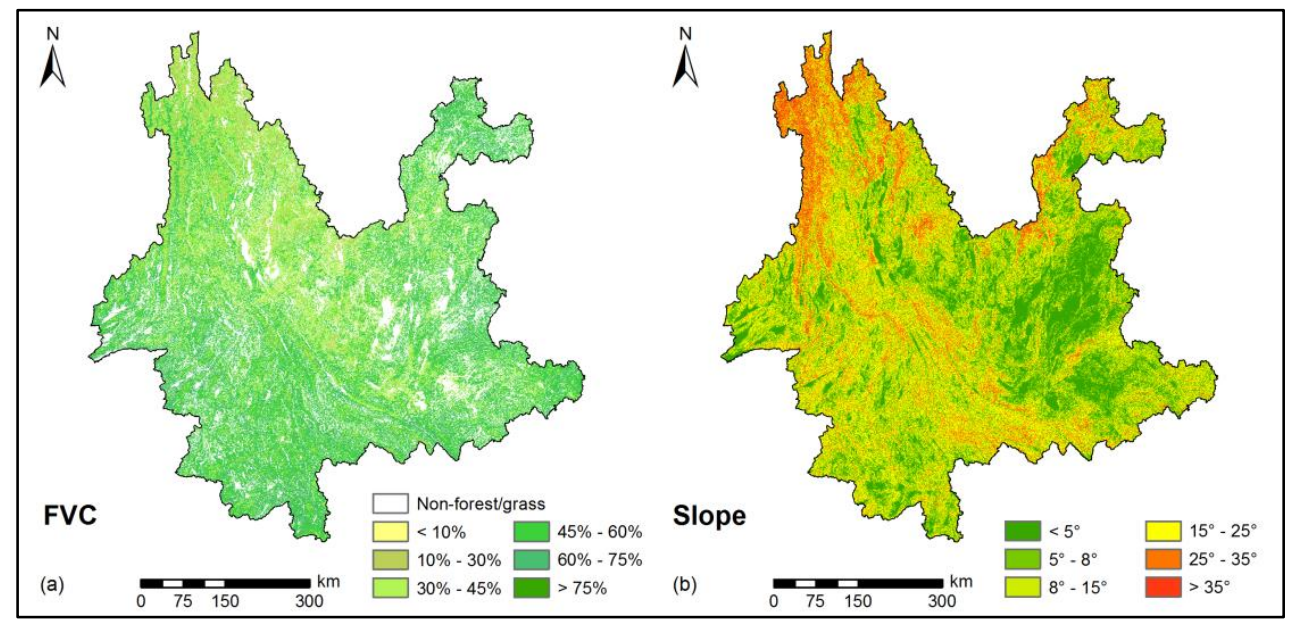

Figure 3. (a) Vegetation fraction cover of Yunnan in 2010; (b) Slope gradient of Yunnan in 2010.

\section{Results}

\subsection{Spatial Distribution of Soil Erosion Factors of CSLE}

Figure 4a reveals the spatial distribution of annual average rainfall erosivity of Yunnan for 1981-2010. The $R$ values were found to range from 794.76 to $8399.38 \mathrm{MJ} \cdot \mathrm{mm} \cdot \mathrm{ha}^{-1} \cdot \mathrm{h}^{-1} \cdot \mathrm{yr}^{-1}$ and with an average of $3415.21 \mathrm{MJ} \cdot \mathrm{mm} \cdot \mathrm{ha}^{-1} \cdot \mathrm{h}^{-1} \cdot \mathrm{yr}^{-1}$. The spatial distribution of the $R$ values showed a significant decreasing trend from the southeast to the northwest. Lower $R$ values were mainly distributed in the northern tip, while higher $R$ values were primarily distributed in the southern portion of the Yunnan. For most areas, the $R$ values were between 2000 to $4000 \mathrm{MJ} \cdot \mathrm{mm} \cdot \mathrm{ha}^{-1} \cdot \mathrm{h}^{-1} \cdot \mathrm{yr}^{-1}$.

The map of $K$-factor showed in Figure $4 \mathrm{~b}$ was calculated by using the USLE method, and the average $K$ value of the study area was $0.0286 \mathrm{t} \cdot \mathrm{ha} \cdot \mathrm{h} \cdot \mathrm{ha}{ }^{-1} \cdot \mathrm{MJ}^{-1} \cdot \mathrm{mm}^{-1}$, varying from 0 to $0.0484 \mathrm{t} \cdot \mathrm{ha} \cdot \mathrm{h} \cdot \mathrm{ha}^{-1} \cdot \mathrm{MJ}^{-1} \cdot \mathrm{mm}^{-1}$, and then the $K$ factor was adjusted by using unit plot and cropland plot data throughout Yunnan. For the six major basins, the $K$ values of the Pearl River Basin were obviously lower than those of the other five basins. Higher $K$ values mostly occur in the northwest portion of Yunnan.

The LS-factors in Figure 4c vary from 0 to 59.19, with a mean value of 9.25. Areas with higher $L S$ values were generally located in western mountainous area and areas with lower $L S$ values mainly located in the Pearl River Basin with relatively gentle slopes. 


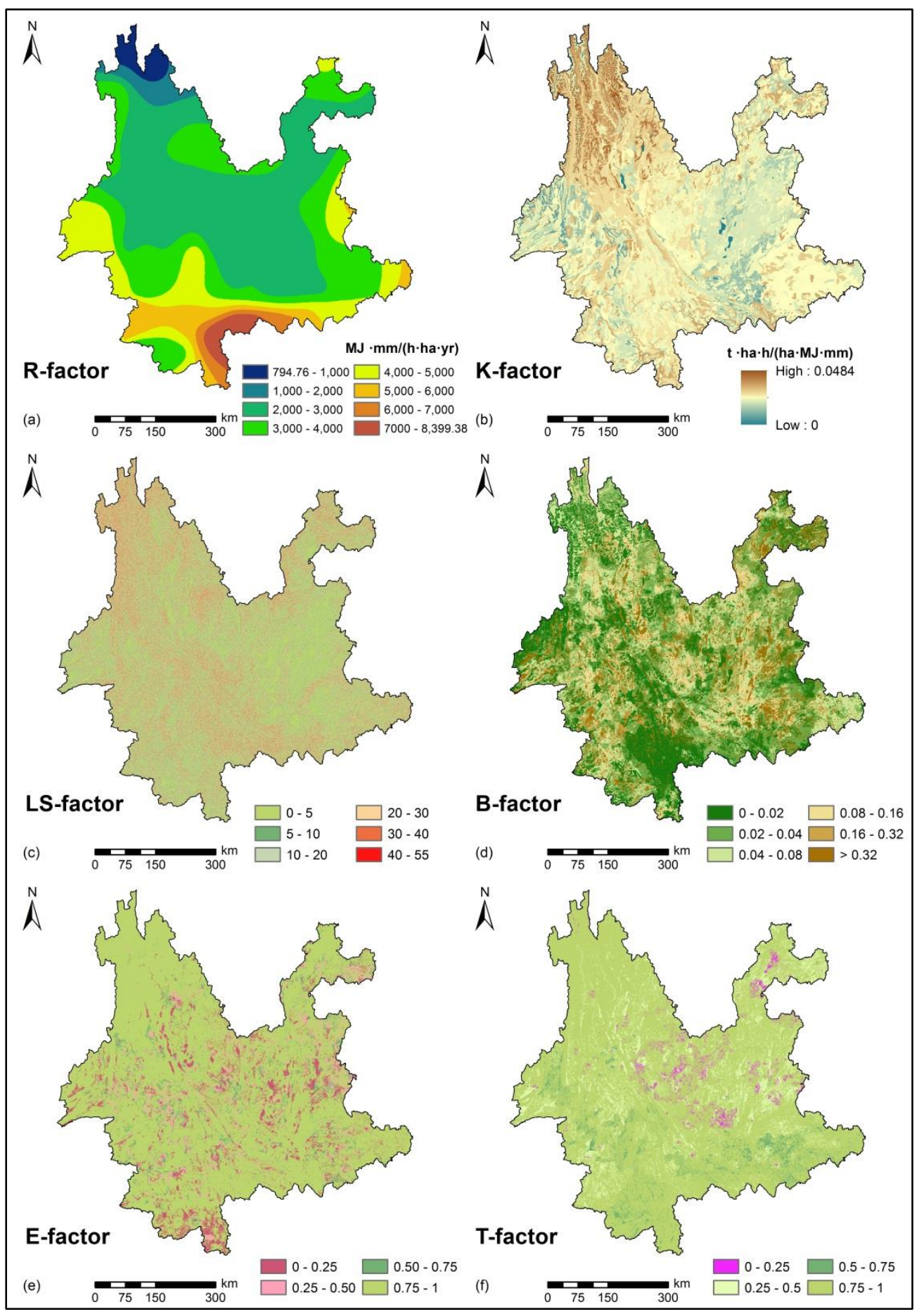

Figure 4. Spatial distribution of soil erosion factors in the Chinese Soil Loss Equation (CSLE) model in Yunnan. (a) Rainfall erosivity; (b) Soil erodibility; (c) Topographic factor; (d) vegetation cover factor; (e) Engineering factor; (d) Tillage factor.

The $B$-factor map in Figure $4 \mathrm{~d}$ was produced using NDVI data. The $B$ values in Yunnan vary from 0 to 1 , with a mean value and standard deviation of 0.049 and 0.067 , respectively. The lower $B$ factor values were found in most of the study area, since the majority of the land was covered by forest and grass. Higher $B$ factor values were only found in arable lands and artificial lands.

The maps of ET-factors in Figure 4e,f were prepared from the PSU data in the national survey and interpolated using land use datasets. Lower ET values were found in the central parts and 
moderate ET values were found in the northern parts, while higher ET values were mainly distributed in southern Yunnan. In other words, arable lands in these areas were treated with less effective soil conservation measures.

\subsection{Spatial Distribution of Soil Erosion in Yunnan}

The spatial pattern of soil erosion rate in Yunnan Province was revealed (Figure 5a) with the relevant parameters of the CSLE model modified as input layers under a geographic information system framework. Erosion rates were then classified into six intensity levels based on SL190-2007 proposed by the Ministry of Water Resources of China. Results showed that $1.48 \times 10^{7}$ ha of land was suffering from erosion with a rate higher than the soil loss tolerance (T) of $5 \mathrm{t} \cdot \mathrm{ha}^{-1} \cdot \mathrm{yr}^{-1}$ in 2010, occupying $38.77 \%$ of the total land area in Yunnan. The average annual soil erosion rate of the province was found to be $12.46 \mathrm{t} \cdot \mathrm{ha}^{-1} \cdot \mathrm{yr}^{-1}$ and the total annual soil loss was about $0.47 \mathrm{Gt}$. Slight, light, moderate, intensive, severe and extreme erosion accounted for $61.23 \%, 28.32 \%, 5.30 \%, 1.98 \%, 1.77 \%$ and $1.39 \%$ of the total land area, respectively. As can be seen in Figure 5a, severe and extreme erosion mainly occurred in the agricultural areas in southern Yunnan, while most areas in central and northern Yunnan fell within the categories of slight and light erosion. The regional variation was significantly impacted by the variation in the annual rainfall erosivity, topographic factors, as well as soil conservation practices adopted in these regions.

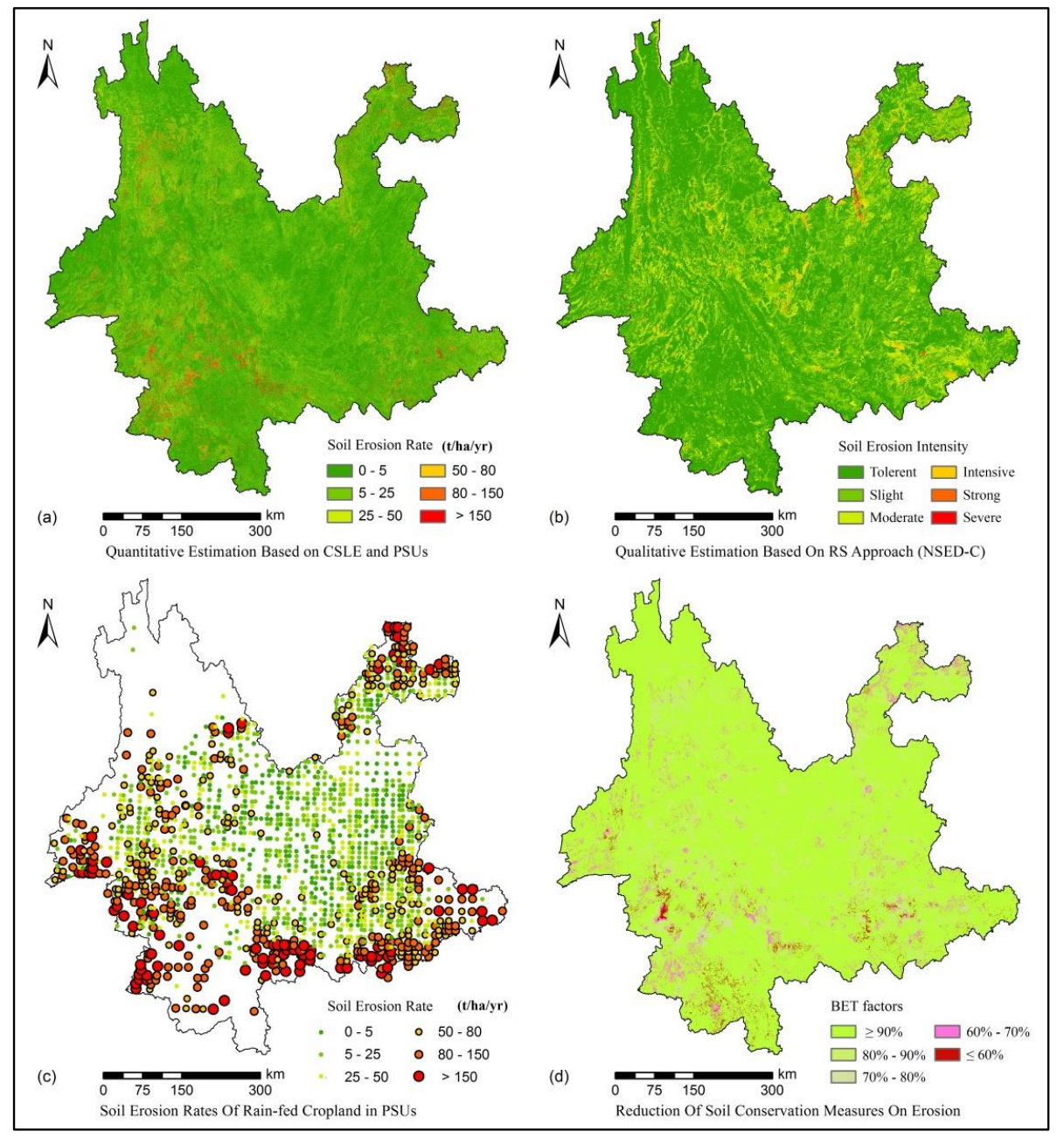

Figure 5. Spatial patterns of soil erosion, erosion intensities and effects of conservation measures. (a) Quantitative CSLE estimation; (b) Qualitative RS estimation; (c) Rain-fed cropland erosion rate in PSUs; (d) Effects of soil conservation measures. 
The CSLE estimates in the study were consistent with the field-based assessment in PSUs. Data from 2010 NSES showed that out of 2871 PSUs in Yunnan, rain-fed cropland parcels were found within 1800 PSUs in the field investigation, the average soil erosion rates of rain-fed cropland in these PSUs were revealed in Figure 5c, which were calculated based on first hand on-site data with higher resolution $(10 \mathrm{~m})$ in the 2010NSES for each PSU [22]. Additionally, the effect of soil conservation measures on erosion reduction is also presented in Figure 5d. The distribution of soil erosion and soil conservation measures adopted showed a close negative correlation. For most areas, the combined soil conservation measures (BET) contributed to a total of $80 \%$ reduction on erosion, while the lower BET-factors generally resulted in severe and extreme erosion intensities. Policymakers should promote anti-erosion measures by financing land management practices, such as terracing, contour cropping, plastic film mulching and furrow planting, which have been proved to be effective on soil erosion reduction in central and northeastern Yunnan [52].

For the six major basins in Yunnan, higher soil erosion intensities generally occurred in the lower reaches of the rivers as compared to the upper reaches, this is mainly because the higher rainfall erosivity and a larger proportion of rain-fed cropland existed in the downstream areas. The erosion ratios (percentage of area eroded with a higher rate than $\mathrm{T}$ in the total land) of the six basins were sorted in descending order as follows: The Mekong $>$ the Salween $>$ the Red $>$ the Yangtze $>$ the Irrawaddy $>$ the Pearl. Results in Table 4 demonstrated that the Mekong River Basin, the Salween River Basin and the Red River Basin were suffering serious soil erosion problems in terms of mean soil erosion rates and soil erosion ratio, while soil erosion of the Pearl River Basin and the Irrawaddy Basin were much optimistic.

Table 4. Soil erosion in the six major river basins in Yunnan.

\begin{tabular}{|c|c|c|c|c|c|c|}
\hline Basin & $\begin{array}{c}\text { Area } \\
\left(10^{4} \mathrm{ha}\right)\end{array}$ & Area \% & $\begin{array}{l}>\mathrm{T} \\
(\%)\end{array}$ & $\begin{array}{c}\text { SLR } \\
\left(\mathrm{t} \mathrm{ha^{-1 }} \mathrm{yr}^{-1}\right)\end{array}$ & $\begin{array}{c}\mathrm{SL} \\
\left(10^{6} \mathrm{t} \mathrm{yr}^{-1}\right)\end{array}$ & $\%$ of TSL \\
\hline Yangtze & 1078.63 & $28.24 \%$ & $37.28 \%$ & 10.19 & 109.89 & $23.31 \%$ \\
\hline Mekong & 882.73 & $23.11 \%$ & $42.83 \%$ & 16.89 & 149.12 & $31.63 \%$ \\
\hline Irrawaddy & 187.10 & $4.90 \%$ & $27.29 \%$ & 9.22 & 17.26 & $3.66 \%$ \\
\hline Salween & 334.57 & $8.76 \%$ & $45.55 \%$ & 14.48 & 48.43 & $10.27 \%$ \\
\hline Pearl & 591.67 & $15.49 \%$ & $31.44 \%$ & 7.66 & 45.31 & $9.61 \%$ \\
\hline Red & 745.01 & $19.50 \%$ & $41.80 \%$ & 13.61 & 101.39 & $21.51 \%$ \\
\hline Yunnan & 3819.70 & $100 \%$ & $38.77 \%$ & 12.46 & 471.40 & $100 \%$ \\
\hline
\end{tabular}

Note: T, soil loss tolerance; SLR, soil loss rates; SL, soil loss; TSL, total sol loss.

\subsection{Soil Erosion Variations under Different Land Use Types in Yunnan}

A spatial analysis of soil loss rates by land use type using the major 2nd level NLUD-C land use classes was made. Results showed that most of the soil erosion took place on rain-fed cropland. The average soil erosion rate for rain-fed cropland $\left(47.69 \mathrm{t} \cdot \mathrm{ha}^{-1} \cdot \mathrm{yr}^{-1}\right)$ was about four times of the overall soil erosion rate $\left(12.46 \mathrm{t} \cdot \mathrm{ha}^{-1} \cdot \mathrm{yr}^{-1}\right)$ in Yunnan. Only $37.56 \%$ of the rain-fed cropland in Yunnan was being eroded with acceptable erosion rate and $64.24 \%$ suffered a soil loss rate higher than $\mathrm{T}$. For the whole province, light, moderate, intensive, severe and extreme erosion accounted for $21.69 \%$ $\left(111.51 \times 10^{4}\right.$ ha), $13.72 \%\left(70.55 \times 10^{4}\right.$ ha $), 9.44 \%\left(48.53 \times 10^{4}\right.$ ha $), 10.48 \%\left(53.89 \times 10^{4}\right.$ ha $)$ and $8.91 \%$ $\left(45.79 \times 10^{4}\right.$ ha) of the rain-fed cropland area in 2010. Consequently, rain-fed cropland accounted for $52.06 \%$ of the total soil loss from all land use types, while it only took up $13.47 \%$ of the total land area in 2010. Grassland and woodland also suffered from serious erosion, $39.20 \%$ of grassland and $36.71 \%$ of woodland in Yunnan were being eroded. Although the erosion rates of woodland and grassland were much lower compared to those from rain-fed cropland, erosion from them should not be underestimated. The annual soil loss from woodland accounted for $35.65 \%$ of the total soil loss as it covered $57.64 \%$ of the land in Yunnan. Grassland covered $22.55 \%$ of the land area and contributed 
to $11.71 \%$ of the total soil loss. To some extent, water bodies, built-up areas and unused land were practically non-erodible, contributing to $0.39 \%$ of the total soil loss with $2.01 \%$ of the total land area.

The average soil loss rates for the major 2nd-level NLUD-C land use classes and corresponding share of soil loss were listed in Table 5 . Due to the higher vegetation cover and as a consequence, lower $B$ values, the mean soil erosion rates for forest $\left(4.46 \mathrm{t} \cdot \mathrm{ha}^{-1} \cdot \mathrm{yr}^{-1}\right)$ and dense grass $\left(5.80 \mathrm{t} \cdot \mathrm{ha}^{-1} \cdot \mathrm{yr}^{-1}\right)$ were acceptable. Areas covered by paddy, forest and dense grass showed relatively lower erosion ratio compare to other 2nd-level types. Moderate grass and shrub had a similar erosion ratio (about $42 \%$ ) and moderate erosion rates among all 2nd-level types. Erosion on sparse woods and sparse grass were noticeable, particularly sparse woods that distributed in high attitudes. Despite the low $B$-factor, sparse woods were characterized with soil erosion rate $\left(14.53 \mathrm{t} \cdot \mathrm{ha}^{-1} \cdot \mathrm{yr}^{-1}\right)$ and soil loss contribution ratio $(15.39 \%)$ only ranked behind rain-fed cropland. The major reason behind is many of the sloping orchards and tea gardens (classed in sparse woods in the NLUD-C classification) resemble the rain-fed cropland in terms of management and cultivation, resulting in serious erosion problems. Meanwhile, this is the most uncertain land-cover class due to the ambiguity between the NLUD-C land cover classification and the field survey. Anti-erosion measures should be promoted to sparse woods, especially sloping gardens as the large proportion in Yunnan and the considerable soil loss yielded. The CSLE estimates under different land use types compare well with local measurements from Yang et al. [53] under experimental plots.

Table 5. Mean soil loss rates for different land uses and corresponding shares of soil loss.

\begin{tabular}{|c|c|c|c|c|c|c|}
\hline Land Use & $\begin{array}{c}\text { Area } \\
\left(10^{4} \mathrm{ha}\right)\end{array}$ & Area \% & $\begin{array}{l}>\mathrm{T} \\
(\%)\end{array}$ & $\begin{array}{c}\text { SLR } \\
\left(\mathrm{t} \cdot \mathrm{ha}^{-1} \cdot \mathrm{yr}^{-1}\right)\end{array}$ & $\begin{array}{c}\text { SL } \\
\left(10^{4} t \cdot y^{-1}\right)\end{array}$ & $\%$ of TSL \\
\hline Paddy & 165.44 & $4.33 \%$ & $1.58 \%$ & 0.54 & 88.7 & $0.19 \%$ \\
\hline $\begin{array}{l}\text { Rain-fed } \\
\text { cropland }\end{array}$ & 514.54 & $13.47 \%$ & $64.24 \%$ & 47.69 & 24539.2 & $52.06 \%$ \\
\hline Forest & 849.69 & $22.24 \%$ & $26.52 \%$ & 4.46 & 3792.0 & $8.04 \%$ \\
\hline Shrub & 852.94 & $22.33 \%$ & $42.08 \%$ & 6.75 & 5760.4 & $12.22 \%$ \\
\hline Sparse woods & 499.22 & $13.07 \%$ & $44.85 \%$ & 14.53 & 7255.0 & $15.39 \%$ \\
\hline Dense grass & 540.55 & $14.15 \%$ & $36.77 \%$ & 5.80 & 3134.4 & $6.65 \%$ \\
\hline Moderate grass & 295.48 & $7.74 \%$ & $42.40 \%$ & 7.16 & 2115.2 & $4.49 \%$ \\
\hline Sparse grass & 25.19 & $0.66 \%$ & $53.98 \%$ & 10.77 & 271.4 & $0.58 \%$ \\
\hline Water Bodies & 27.90 & $0.73 \%$ & 0 & 0 & 0 & 0 \\
\hline Built-up land & 28.20 & $0.74 \%$ & $3.81 \%$ & 1.18 & 33.2 & $0.07 \%$ \\
\hline Unused land & 20.56 & $0.54 \%$ & $4.71 \%$ & 7.35 & 151.2 & $0.32 \%$ \\
\hline
\end{tabular}

Note: The 11 land-use types listed above are summarized based on the classification systems prescribed in the NLUD-C and area proportion. Arable land, woodland and grassland are major 1st-level types and divided into 2nd-level types as they occupy about $98 \%$ of the province. Arable land consists of paddy and rain-fed cropland; Woodland consists of forest, shrub and sparse woods; Grasslands includes dense grass, moderate grass and sparse grass; water surface, built-up land and unused land remain 1st-level types as the low area proportion in Yunnan. T, soil loss tolerance; SLR, soil loss rates; SL, soil loss; TSL, total sol loss.

Significant regional differences of rain-fed cropland in soil erosion rates were also found among the six major river basins, rain-fed croplands in the basins of the Mekong, the Salween, the Red and the Irrawaddy showed obviously higher rates than those of the other two basins, with an average annual soil erosion rate of $69.79,53.78,54.25$ and $52.20 \mathrm{t} \cdot \mathrm{ha}^{-1} \cdot \mathrm{yr}^{-1}$ respectively, while rain-fed cropland in the Yangtze River Basin and the Pearl River Basin experienced respective erosion rate of $35.06 \mathrm{t} \cdot \mathrm{ha}^{-1} \cdot \mathrm{yr}^{-1}$ and $23.42 \mathrm{t} \cdot \mathrm{ha}^{-1} \cdot \mathrm{yr}^{-1}$. This is mostly due to the high rainfall intensity and the steep slopes for the former basins, while special attention was given to slope cropland in the lower reaches of the Yangtze, which has been listed as the key priority for ecological construction and soil conservation for three decades, rain-fed cropland of the Pearl River Basin experiences relative gentle slopes, lower soil erodibility and complete soil conservation systems. For all the basins, rain-fed cropland in the downstream areas generally suffers a higher soil loss rate than the upstream areas. 


\subsection{Comparison of Predicted Soil Loss Rates with the Estimates of Qualitative RS Method}

Figure $5 b$ shows the estimates in the National Soil Erosion Database of China (NSED-C) using qualitative integrated evaluation method (hereinafter referred to as the RS method). The qualitative RS method uses indicators of the slope, vegetation coverage of different land uses to grade the soil erosion intensity. The spatial pattern of soil erosion mapped by means of the CSLE method and the RS method have certain similarities and differences in the present study. Both mapping methods resulted in lower erosion rates in arable lands in the central portion of the study area, which can lead to greater attention given soil and water conservation measures adopted in these areas. Because of the difference in soil erosion affecting factors considered, erosion hot spots identified in the southeast and southwest by the CSLE method were experiencing much more severe erosion than those identified by the RS method. Estimates of the qualitative RS method showed that the soil erosion ratio of the province in 2010 was $36.72 \%$, light, moderate, intensive, severe and extreme erosion accounted for $20.65 \%, 13.78 \%, 2.14 \%$, $0.11 \%$ and $0.05 \%$ of the province, respectively. The erosion ratios for the major 2 nd-level land use types were sorted in descending order as follows: Rain-fed cropland $(64.78 \%)>$ moderate grass $(59.62 \%)$ $>$ dense grass $(57.24 \%)>$ sparse grass $(40.60 \%)>$ sparse woods $(31.56 \%)>$ paddy $(30.43 \%)>$ shrub $(29.82 \%)>$ forest $(10.97 \%)$.

Figure 6 shows the 1st-level land use composition of each soil erosion intensity level for the two estimates using different approaches. Woodland appeared to be the most dominant land type in relative lower intensities (slight, light and moderate) for both estimates. As can be seen in Figure 6a, the proportions of woodland and grassland showed a declining trend as the erosion intensity increases for CSLE estimates. The situation is totally opposite for arable land, which contributed to $86.09 \%$ of the extreme erosion area, $79.61 \%$ of the severe erosion area, $64.08 \%$ of the intensive erosion area. For the quantitative method, severe and extreme erosion mostly occurred in rain-fed cropland and sparse woods. However, for the qualitative estimates, a similar trend (Figure 6b) as arable land in the former situation was found on grassland, which indicated that grassland in Yunnan was being eroded with higher erosion intensity levels than other types.

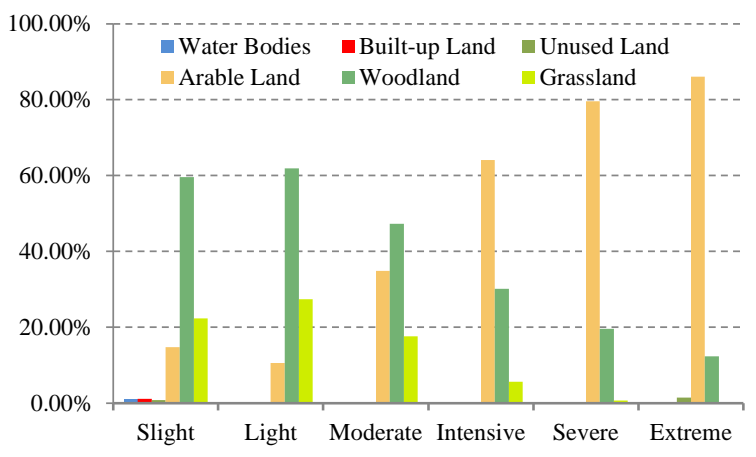

(a)

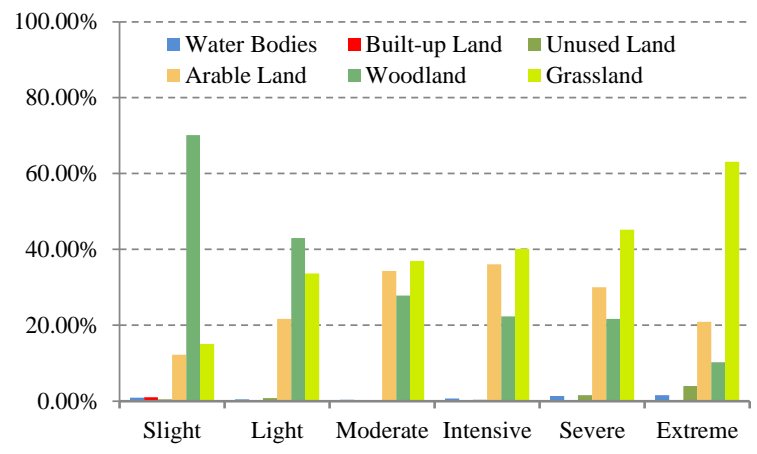

(b)

Figure 6. Land use composition of each soil erosion intensity for the two estimates: (a). Land use composition of each erosion intensity (CSLE); (b). Land use composition of each erosion intensity (RS).

The difference was analyzed by subtracting the CSLE estimates from the qualitative RS method estimates. Of the total land, $47.72 \%$ showed no difference in soil erosion intensity for the two results. Land with differences of 1 erosion intensity level and 2 erosion intensity levels accounted for $35.54 \%$ and $12.09 \%$, respectively. Differences of three or more erosion intensity levels accounted for $4.65 \%$. For the six first-level land use types, the difference ratio of arable land $(64.15 \%)$ between the two estimates was the highest, followed by grassland (63.74\%) and woodland (45.09\%), built-up land, unused land and water bodies generally show a difference ratio less than $20 \%$.

These differences can be explained as following specific reasons. First, the qualitative RS method applied in NSED-C uses DEM of $100 \mathrm{~m}$ cell size to generate topographic index at the national scale, 
which was very coarse for mountainous areas like Yunnan and will inevitably cause a decline in slope gradient and arable land erosion, since slope gradient is the only basis to grade erosion intensity for arable land in the RS method. Besides, vegetation indexes derived from the qualitative RS method only represent the vegetation cover growing season (from day 193 to day 225), which cannot reflect the seasonal variation for both vegetation and rainfall and may lead to uncertainties for land use types with a permanent cover. These are the major causes directly related to the underestimation of soil erosion and priority areas identified by the RS method compared with the CSLE estimates. Lastly, many sloping gardens (classified as sparse woods) in Yunnan, especially tea gardens, resemble arable land in terms of cultivation pattern, and suffer from the same serious soil erosion as the slope cropland [54]. But the qualitative method treats the gardens as forests in terms of intensity grading, which leads to lower intensity levels than the CSLE method. For grassland erosion, the qualitative estimates were overestimated compared to the quantitative CSLE estimates. This is mainly because grasslands mostly located in highlands with steep slopes in the northwest portion, whereas rainfall erosivity appeared to be the lowest in the province, while rainfall was not taken into account in the qualitative RS method.

\subsection{Policy Interventions on Rain-Fed Cropland Soil Erosion Reduction}

The spatial pattern of rain-fed cropland erosion rate generally describes the outline of the actual erosion situation in Yunnan. In order to evaluate the effects of policy interventions on soil erosion reduction, a cross-comparison was made to compare the CSLE estimates in the present study with previous local assessments conducted by Yang et al. [55]. We reclassified the erosion grades and divided the province into five agricultural regions according to their study and statistics on soil erosion rate were made at a county level. Figure 7a shows the spatial distribution of soil erosion rate from rain-fed cropland in 2006, which was produced using a method incorporating local soil loss equation, measurements under experimental plots and a provincial land use investigation [55]. Figure $7 \mathrm{~b}$ presents the spatial distribution of soil erosion rate from rain-fed cropland in this study in 2010. The two field-based quantitative approaches to assessing soil erosion related well with each other in terms of the spatial pattern of erosion rate. The most significant sheet and rill erosion hot spots were located in the SW region for both estimates, soil loss from this region accounted for $37.1 \%$ and $48.67 \%$ of the total soil loss for each estimate, due to a large proportion of rain-fed cropland in this region. For most areas, soil erosion from rain-fed cropland showed a significant declining trend from 2006 to 2010, especially in the northeast and central portions of the province. Of the counties in the province, $44.8 \%$ (56 out of 125 ) showed a decline in erosion grades in 2010 compared to $2006,36 \%$ (45 out of 125) of the counties remains the same erosion grades for the two estimates and the remaining $19.2 \%$ (24 out of 125 ) of the counties shows an increase in erosion grades, mostly in the southern areas. For the whole province, the average annual sheet and rill erosion rate on rain-fed cropland fell from $59.65 \mathrm{t} \cdot \mathrm{ha}^{-1} \cdot \mathrm{yr}^{-1}$ in 2006 to $\mathrm{t} \cdot \mathrm{ha}^{-1} \cdot \mathrm{yr}^{-1}$ in 2010 , with a $20 \%$ decrease. For the five agricultural regions, erosion rate on rain-fed cropland has dramatically changed in the NE (from 78.84 to $45.37 \mathrm{t} \cdot \mathrm{ha}^{-1} \cdot \mathrm{yr}^{-1}$ ), NW (from 70.41 to $57.80 \mathrm{t} \cdot \mathrm{ha}^{-1} \cdot \mathrm{yr}^{-1}$ ), Central (from 38.91 to $21.01 \mathrm{t} \cdot \mathrm{ha}^{-1} \cdot \mathrm{yr}^{-1}$ ) and SE (from 56.58 to $\left.53.86 \mathrm{t} \cdot \mathrm{ha}^{-1} \cdot \mathrm{yr}^{-1}\right)$ regions, while only in SW Region, the soil erosion rate remains the same level (68.94 to $\left.69.00 \mathrm{t} \cdot \mathrm{ha}^{-1} \cdot \mathrm{yr}^{-1}\right)$. As a result, annual soil loss from rain-fed cropland has decreased from $3.63 \times 10^{8} \mathrm{t}$ in 2006 to $2.46 \times 10^{8} \mathrm{t}$ in the present study, with a $32 \%$ decrease. 


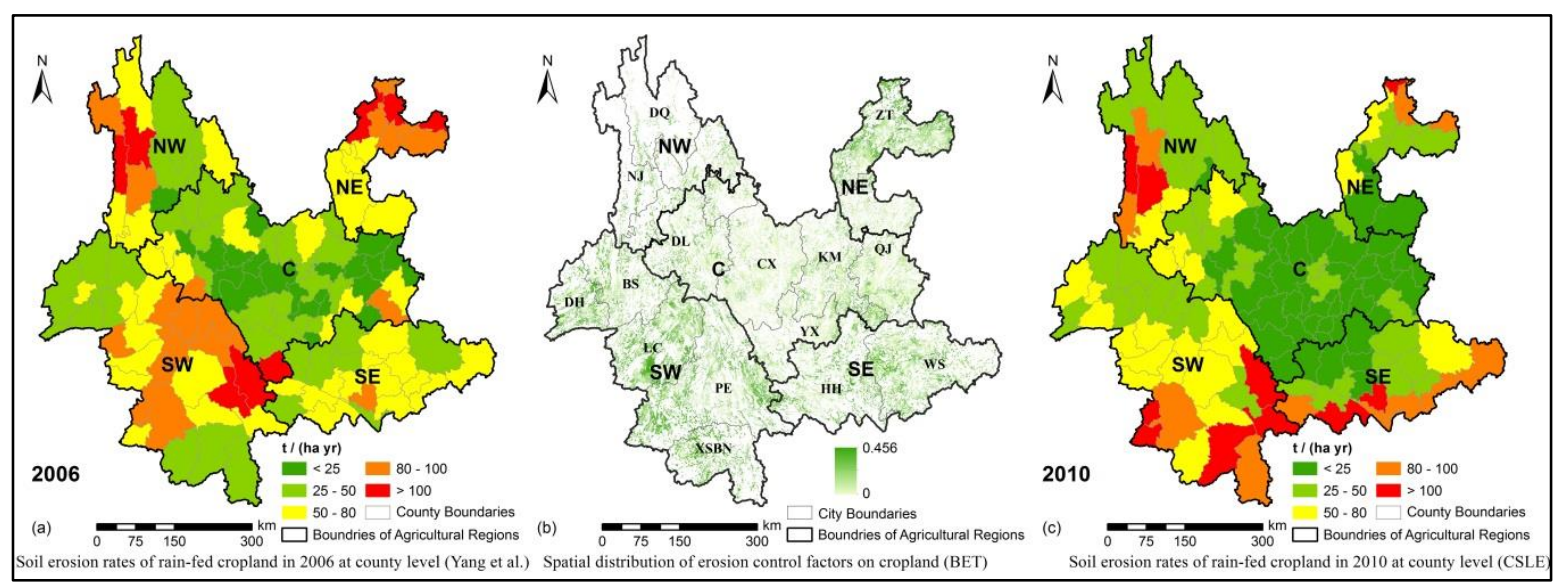

Figure 7. Spatial changes of cropland erosion at county level in Yunnan. (a) Rain-fed cropland erosion rate in 2006; Effects of erosion control measures; (c) Rain-fed cropland erosion rate in 2010.

The reduction in soil erosion rate can be attributed to two factors: Improved conservation practice on cropland and conversion of slope cropland $\left(>5^{\circ}\right)$ to forest or grass. During the last decade, policies, such as the Grain-for-Green Program (GFGP) [56,57], a project of returning steep slope cropland to forest/grass, policy of transforming slope land into the terraced field and other local soil conservation projects have dramatically improved the soil conservation benefits in the province. Figure $7 \mathrm{~b}$ presents the spatial pattern of soil erosion control measure effects for a combination of vegetation cover practice (B-factor), engineering practice (E-factor) and tillage practice (T-factor) on cropland in 2010. The average erosion control factors (BET) for cropland of the province was 0.174 , which means that soil conservation measures adopted in cropland have reduced the total soil loss by $82.6 \%$ compared to the potential soil erosion risk. For the five agricultural regions, the respective values for the NE, NW, SW, SE and Central regions were $0.189,0.199,0.233,0.196$ and 0.101 . As can be seen, the central region showed the lowest value which can be explained as complete conservation systems and the largest portion of paddy existed in this area. Meanwhile, the NE agricultural region showed the second lowest value, due to the special attention given to slope cropland in the Yangtze River Basin, which has been listed as one of the key priorities for soil conservation and ecological construction in the country. However, according to Yang's earlier studies [58], the NE region was known for extreme soil erosion before, since slope cropland accounted for $94.52 \%$ of the total cropland in the area and $87.87 \%$ of these slope cropland was absent of any soil and water conservation measures. Moreover, only about $20 \%$ of the land in this area was covered with forest and grass before.

The other major reason contributed to the decline was the changes in slope cropland areas. It is reported that about $2.4 \times 10^{5} \mathrm{~km}^{2}$ of slope farmland existed in China, which causes a total soil loss of about 1.42 billion tons each year and accounts for nearly one-third of the total soil loss of the country [59]. Previous study [60] has confirmed that cropland is the most important source of soil loss in China and erosion rates from slope cropland can be tens to hundreds of times of those from grassland. As can be seen in Figure 8, the slope cropland area in Yunnan has fellen from $410 \times 10^{4}$ ha in 1997 to $377.1 \times 10^{4}$ ha in 2010 , with an $8 \%$ decrease. The decrease mainly distributed in QJ and KM (The Central region), WS and HH (the SE region) and ZT (the NE region). The year 1997 was selected as a reference because it was the closest year that Yunnan conducted a detailed land use survey before the Grain-for-Green Program (GFGP) started in 1999. 


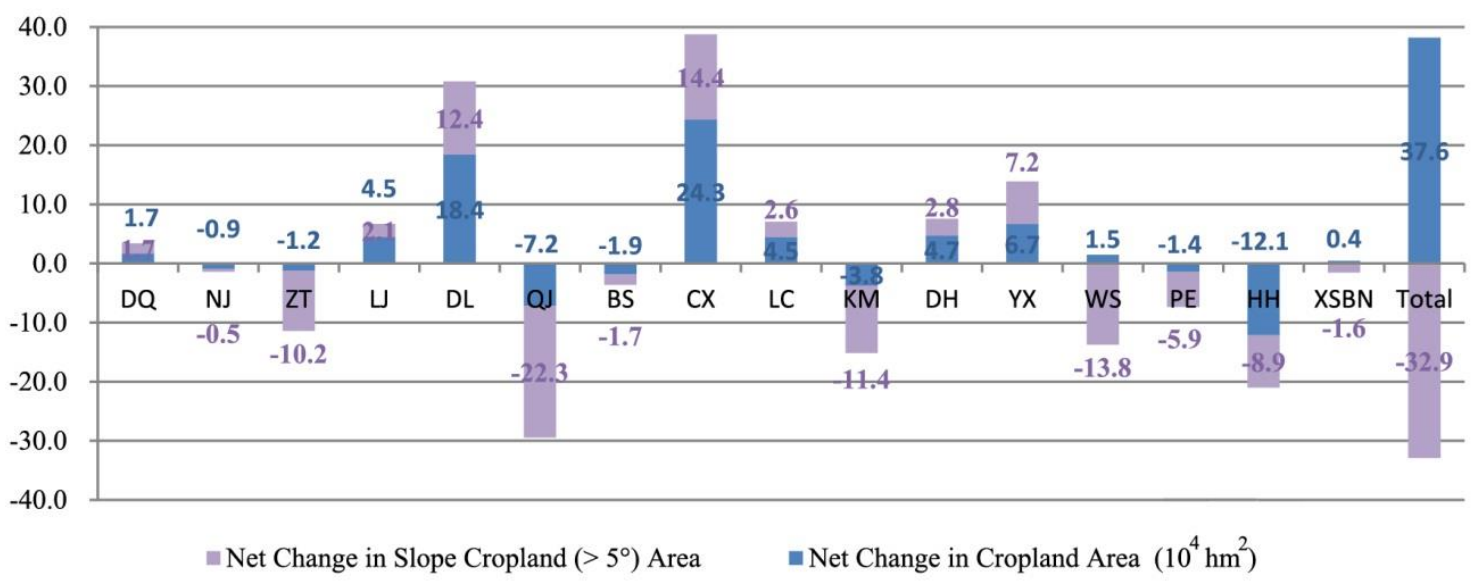

Figure 8. Changes in cropland areas for the 16 municipal districts in Yunnan during 1997-2010.

However, the pressure from population growth on remaining land resources is very high, to meet the greater demand for food, the cropland area showed a remarkable increasing trend, from $642 \times 10^{4}$ ha in 1997 to $679.6 \times 10^{4}$ ha in 2010 , with a $5.86 \%$ increase. The increased slope cropland area mostly concentrated in CX, DL and YX of the Central region. As can be seen in Table 6, the relative lower erosion control factors values in these districts suggested that high soil conservation efficiency existed in cropland. However, even the slope land in the Central region showed the lowest erosion rate among the five regions, it was still several times above the tolerant erosion rate. Moreover, LC and DH of the SW Region, DQ and NJ of the NW Region were also involved in increased slope cropland, which should not be neglected because of the relative higher erosion control factors (lower erosion control efficiency) in these areas. Policy interventions have reduced the slope cropland proportion remarkably, still, only 5 out of 16 municipal districts with a slope land percentage lower than $50 \%$ and a total of $53.01 \times 10^{4}$ ha of cropland in Yunnan were still located on slopes $>25^{\circ}$. Since about $84 \%$ of the province was classed as mountainous landscape and the plain areas already fully utilized for agriculture, which will inevitably lead to the expansion and creation of new cropland onto steep slopes. To further reduce soil erosion on cropland and thereby mitigate the environmental and social implications, policy options, such as technical assistance and education should be available to induce farmers to implement soil conservation measures.

Table 6. Cropland erosion control effects and slope cropland percentage for the 16 districts in 2010.

\begin{tabular}{cccccccc}
\hline District & BET & $\begin{array}{c}\text { SC \% } \\
\mathbf{( 1 9 9 7 )}\end{array}$ & $\begin{array}{c}\text { SC } \% \\
\mathbf{( 2 0 1 0 )}\end{array}$ & District & BET & $\begin{array}{r}\text { SC \% } \\
\mathbf{( 1 9 9 7 )}\end{array}$ & $\begin{array}{c}\text { SC } \% \\
\mathbf{( 2 0 0 0 )}\end{array}$ \\
\hline DQ & 0.217 & $71 \%$ & $77 \%$ & LC & 0.237 & $77 \%$ & $75 \%$ \\
NJ & 0.248 & $88 \%$ & $92 \%$ & KM & 0.127 & $59 \%$ & $37 \%$ \\
ZT & 0.212 & $86 \%$ & $72 \%$ & DH & 0.200 & $35 \%$ & $40 \%$ \\
LJ & 0.144 & $67 \%$ & $63 \%$ & YX & 0.090 & $43 \%$ & $58 \%$ \\
DL & 0.141 & $50 \%$ & $56 \%$ & WS & 0.190 & $65 \%$ & $43 \%$ \\
QJ & 0.093 & $59 \%$ & $32 \%$ & PE & 0.248 & $77 \%$ & $71 \%$ \\
BS & 0.175 & $59 \%$ & $57 \%$ & HH & 0.202 & $55 \%$ & $50 \%$ \\
CX & 0.065 & $52 \%$ & $55 \%$ & XSBN & 0.295 & $48 \%$ & $39 \%$ \\
Yunnan & 0.174 & $64 \%$ & $55 \%$ & - & - & - & - \\
\hline
\end{tabular}

Note: SC $\%$, slope cropland percentage.

\section{Discussion}

The 2010 National Soil Erosion Survey was the first attempt to acquire comprehensive soil erosion data in the field for the whole country in China's history. The year 2010 was selected as the reference year in the present study largely depend on the inter-agency field-based data collection, especially in quantifying the effects of soil conservation measures, the update of National Land Use/Cover 
Database of China was also conducted in this year. It should be noted that the CSLE model was selected because of the data availability and its simplicity. The model has been well studied and widely applied at different scales to estimate soil erosion plan erosion control for different landscapes in China. When comparing the CSLE model with the other erosion empirical methods and qualitative approaches in China, the former gives much more detailed information on erosion rate and soil conservation measures. In other words, CSLE method reflects the actual situation better than the qualitative method in this study, due to the field-based survey. The model also uses secondary data freely available under a Geographic Information System framework as an alternative approach. For the decision makers, the predictable and reliable soil erosion rate is of the utmost importance. However, it would be unwise to use the CSLE model if sufficient input data are not available, since data availability maybe the most important concern in determining the approach selected.

Several problems arise when applying quantitative models at a regional scale, or larger scales. First, a model-based approach implies uncertainties in the process of calculation of the relevant parameters, which is common in all model-based approaches. Additionally, the empirical models only used to predict long term annual soil loss, gully erosion, sediment and landslide are not taken into account. Nevertheless, uncertainties also exist in the qualitative RS method, since remote sensing is a process of reflecting earth surface information through electromagnetic waves, due to the uncertainty of understanding in identifying and interpretation from different people, subjective errors will occur and affect the extraction of information, especially for mountainous areas with complex topography situations. Therefore, in selecting the suitable method for mapping soil erosion, decision makers should consider both the purpose in question and the similarities and differences in spatial patterns of the conservation priority areas that may arise from using different methods. The cross-comparison between the two major approaches (CSLE and RS methods) could identify regions and land use types that further study is needed. The CSLE method provides a better understanding of the erosion situation in Yunnan compared to qualitative RS method, as it takes account into two important factors, the soil conservation practices and the seasonal variability of vegetation and rainfall. In this study, we also compared the CSLE estimates with local assessments based on plot measurements provided credible information for comparison. However, the major limitation of soil erosion estimated at a county level is soil erosion variation within each county is not clear. Despite the affecting factors of rainfall erosivity, soil erodibility and human activities can be similar within the same county, but the topography conditions may vary greatly, which leads to more uncertainty.

The high erosion rate and erosion ratio of sparse woods are mainly because the large area of sloping gardens exist in Yunnan, especially tea gardens in the southern portion, which suffer from almost the same serious soil erosion as arable lands do. Southern Yunnan is known for high temperature and intensive rainfall in the summer, but it is also where tea gardens and orchards concentrated. Based on our field investigation, most of these gardens are planted same as row crops, besides, since many slope croplands in the province have been converted into fruit garden for farmers, in order to gain more income, some farmers still use the same cultivation pattern as arable land. According to the study [54] of local experts in 2004, the percentage of the soil erosion area in the garden and forest land even reached $40.92 \%$ and $36.24 \%$ respectively. Moreover, the average soil erosion rate for garden and forest land reached 22.01 and $7.07 \mathrm{t} \cdot \mathrm{ha}^{-1} \cdot \mathrm{y}^{-1}$, which were much higher than the respective value of 14.53 and $4.46 \mathrm{t} \cdot \mathrm{ha}^{-1} \cdot \mathrm{y}^{-1}$ in the present study. The interpretation of Landsat OLI images showed that very high vegetation cover existed in woodlands, but little ground cover actually found in the field survey. Serious erosion also occurred in the purely man-made forests, open forests and young forests in the province.

\section{Conclusions}

Quantitative soil loss assessment is one of the important scientific foundations for land resources management and soil conservation planning, especially for mountainous areas. Largely based on the latest 2010 National Soil erosion Survey, 2010 National Land Use Update, as well as the national soil 
investigation and other data sources, a quantitative pixel-based estimation was made using the CSLE model to produce the soil erosion map of Yunnan Province at $30 \mathrm{~m}$ resolution for the reference year of 2010. The spatial pattern of soil erosion, erosion variation under different land use types and the impact of soil conservation practices were well analyzed. The erosion hot spots were identified and compared with the qualitative results from NSED-C. Meanwhile, a comparison between the 2010 CSLE estimates and local assessments in 2006 at a county level was made to reveal the soil erosion change. Soil erosion rates in the five agricultural regions, six major river basins and 11 major land use types in Yunnan Province were estimated and clarified. Lastly, differences and uncertainties for the soil erosion assessing approaches were discussed. The main findings are summarized as follows:

(1) Yunnan has a mean annual soil loss rate of $12.46 \mathrm{t} \cdot \mathrm{ha} \mathrm{a}^{-1} \cdot \mathrm{y}^{-1}$ and $38.77 \%$ of the total land was being eroded at a rate higher than the soil loss tolerance. As a result, the total annual soil loss of the province was estimated at around $0.47 \mathrm{Gt}$. The results of CSLE compared well with national data reported in the 2010 national soil erosion survey. Extreme and severe erosion were mostly found in the southern agricultural areas, while the central and the northern potions mostly fell within the light and moderate erosion categories. For the six river basins, the downstream areas generally suffered more serious erosion than the upstream areas, which can be attributed to two reasons, the large portion of cropland in the downstream areas and higher rainfall erosivity, especially for the lower reaches of the Mekong, the Salween and the Red rivers. CSLE was found to be a suitable approach for estimating soil loss at the regional scale for the mountainous region

(2) Spatial analysis by land use types demonstrated that rain-fed cropland suffered the most severe erosion in 2010, with a mean erosion rate of $47.69 \mathrm{t} \cdot \mathrm{ha}^{-1} \cdot \mathrm{y}^{-1}$ and an erosion ratio of $64.24 \%$. Soil loss from rain-fed cropland accounted for more than $52 \%$ of the total soil loss from all land use types, while rain-fed cropland only occupied $13.47 \%$ of the total land area. Special attention should be given to the sparse woodland and the $8.91 \%$ (about $45.79 \times 10^{4}$ ha) of rain-fed cropland that were being eroded with irreversible rates of soil loss $\left(>150 \mathrm{t} \cdot \mathrm{ha}^{-1} \cdot \mathrm{y}^{-1}\right)$. Meanwhile, policymakers should not underestimate soil erosion from land with a permanent vegetation cover in Yunnan, although the soil loss rates for most woodland and grassland were not comparable with those on rain-fed cropland, still, about $39.20 \%$ of the grassland and $36.71 \%$ of the woodland had unsustainable mean soil loss rates $>5 \mathrm{t} \cdot \mathrm{ha}^{-1} \cdot \mathrm{y}^{-1}$. Soil erosion from sparse woods (followed only after rain-fed cropland) was noticeable. This is mainly because many slope horticultural lands existed in the province, especially tea gardens and slope fruit gardens, which basically used the same cultivation pattern as farmland.

(3) The comparisons between the CSLE estimates and the NSED-C estimates indicated that soil erosion in rain-fed cropland, sparse woods and grassland distributed in the highlands need further study and the estimates of NSED-C should be interpreted carefully. Compared with local assessments and measurements under experimental plots in literature, the SW region still suffered from serious erosion problem while the other four regions showed a remarkable decline in erosion, especially for the NE region. It is estimated that policy interventions have reduced soil erosion on rain-fed cropland by $20 \%$ in erosion rate and $32 \%$ in total soil loss compared to the local estimates in 2006 . However, even with this reduction, soil erosion rate from rain-fed cropland is still several times above the acceptable rate. As the pressure of population and urban growth keeps driving rain-fed cropland onto increasingly steep slopes, effective soil remediation measures and soil conservation are necessary for most areas to maintain sustainable agriculture, since more than half of the districts in the province still had a slope cropland ratio greater than $50 \%$. Besides, Yunnan is still the province with the largest slope cropland area in the country.

(4) The major advantage of this study is we integrated the field-based investigation of soil conservation measures into soil loss estimation. Although the interpretation of aerial photographs allows the detection of many conservation measures, so far there have been few studies on the application. Meanwhile, time series remote sensing data and meteorological satellite should also be incorporated in erosion assessments to save the high time and labor requirement to make a field survey. Therefore, close collaboration between the field-based erosion scientists and the remote 
sensing community is required for the further erosion assessment at a regional scale, and larger scales. CSLE was found to be a suitable approach for estimating soil loss at the regional scale for the mountainous region, it is hoped that the results of this study will be of interest to those involved in the management of soil resources in Yunnan.

Author Contributions: G.C. derived the CSLE factors and wrote the manuscript, Z.Z. designed the framework of the research; Q.G. contributed extensively to data processing and analysis; X.W. and Q.W. have given many suggestions for improving and modifying this paper. All the authors were involved in result analysis and discussion.

Funding: This research was funded by the National Key Research and Development Plan of China National Key Research and Development Plan of China (NO. 2017YFC0504201) and the Land Use Products Application and Analysis Project of "One-Three-Five" Strategic Planning (Y4SG0300CX).

Acknowledgments: Thanks to the field data gatherers in the National Soil Erosion Survey and Baoyuan Liu and Yun Xie from Beijing Normal University for their invaluable efforts.

Conflicts of Interest: The authors declare no conflict of interest.

\section{References}

1. Pimentel, D. World Soil Erosion and Conservation; Cambridge University Press: Cambridge, UK, 1993.

2. Lal, R. Soil erosion and the global carbon budget. Environment Int. 2003, 29, 437-450. [CrossRef]

3. Pimentel, D.; Burgess, M. Soil erosion threatens food production. Agriculture 2013, 3, 443-463. [CrossRef]

4. Pimentel, D.; Harvey, C.; Resosudarmo, P.; Sinclair, K.; Kurz, D.; Mcnair, M.; Crist, S.; Shpritz, L.; Fitton, L.; Saffouri, R. Environmental and economic costs of soil erosion and conservation benefits. Science 1995, 267, 1117-1123. [CrossRef] [PubMed]

5. Morgan, R.P.C. Soil Erosion and Conservation; John Wiley \& Sons: Hoboken, NJ, USA, 2009.

6. De Vente, J.; Poesen, J.; Verstraeten, G.; Govers, G.; Vanmaercke, M.; Van Rompaey, A.; Arabkhedri, M.; Boix-Fayos, C. Predicting soil erosion and sediment yield at regional scales: Where do we stand? Earth Sci. Rev. 2013, 127, 16-29. [CrossRef]

7. Uri, N.D. Agriculture and the environment-the problem of soil erosion. J. Sustain. Agric. 2000, 16, 71-94. [CrossRef]

8. Bridges, E.M.; Oldeman, L.R. Global assessment of human-induced soil degradation. Arid Soil Res. Rehabil. 1999, 13, 319-325. [CrossRef]

9. Boardman, J.; Poesen, J. Soil Erosion Risk in Europe; John Wiley \& Sons: Hoboken, NJ, USA, 2007.

10. Vrieling, A. Satellite remote sensing for water erosion assessment: A review. Catena 2006, 65, 2-18. [CrossRef]

11. Gobin, A.; Jones, R.; Kirkby, M.; Campling, P.; Govers, G.; Kosmas, C.; Gentile, A. Indicators for pan-European assessment and monitoring of soil erosion by water. Environ. Sci. Policy 2004, 7, 25-38. [CrossRef]

12. Wang, X.; Zhao, X.; Zhang, Z.; Yi, L.; Zuo, L.; Wen, Q.; Liu, F.; Xu, J.; Hu, S.; Liu, B. Assessment of soil erosion change and its relationships with land use/cover change in China from the end of the 1980s to 2010. Catena 2016, 137, 256-268. [CrossRef]

13. De Vente, J.; Poesen, J.; Verstraeten, G.; Van Rompaey, A.; Govers, G. Spatially distributed modelling of soil erosion and sediment yield at regional scales in Spain. Glob. Planet. Chang. 2008, 60, 393-415. [CrossRef]

14. Liu, B.Y.; Guo, S.Y.; Li, Z.G.; Xie, Y.; Zhang, K.L.; Liu, X.C. Sampling survey of water erosion in China. Soil Water Conserv. China 2013, 01, 26-34. (in Chinese).

15. Morgan, R.P.C.; Nearing, M.A. Handbook of Erosion Modelling; John Wiley \& Sons: Hoboken, NJ, USA, 2011.

16. Nusser, S.; Goebel, J. The national resources inventory: A long-term multi-resource monitoring programme. Environ. Ecol. Stat. 1997, 4, 181-204. [CrossRef]

17. Renard, K.G.; Foster, G.R.; Weesies, G.A.; Porter, J.P. Rusle: Revised universal soil loss equation. J. Soil Water Conserv. 1991, 46, 30-33.

18. Renard, K.G.; Foster, G.R.; Weesies, G.; McCool, D.; Yoder, D. Predicting Soil Erosion by Water: A Guide to Conservation Planning with the Revised Universal Soil Loss Equation (RUSLE); US Government Printing Office: Washington, DC, USA, 1997; Volume 703.

19. Cerdan, O.; Govers, G.; Le Bissonnais, Y.; Van Oost, K.; Poesen, J.; Saby, N.; Gobin, A.; Vacca, A.; Quinton, J.; Auerswald, K. Rates and spatial variations of soil erosion in Europe: A study based on erosion plot data. Geomorphology 2010, 122, 167-177. [CrossRef] 
20. Guo, Q.; Hao, Y.; Liu, B. Rates of soil erosion in China: A study based on runoff plot data. Catena 2015, 124, 68-76. [CrossRef]

21. Evans, R.; Collins, A.; Foster, I.D.; Rickson, R.; Anthony, S.; Brewer, T.; Deeks, L.; Newell-Price, J.; Truckell, I.; Zhang, Y. Extent, frequency and rate of water erosion of arable land in britain-benefits and challenges for modelling. Soil Use Manag. 2016, 32, 149-161. [CrossRef]

22. Xie, Y.; Lin, H.; Ye, Y.; Ren, X. Changes in soil erosion in cropland in northeastern China over the past 300 years. Catena 2019, 176, 410-418. [CrossRef]

23. Li, Z.G.; Fu, S.H.; Liu, B.Y. Sampling program of water erosion inventory in the first national water resource survey. Sci. Soil Water Conserv. 2012, 10, 77-81. (in Chinese).

24. Oldeman, L.R.; Hakkeling, R.u.; Sombroek, W.G. World map of the status of human-induced soil degradation: An explanatory note. Global assessment of soil degradation (glasod); UN Envirnment: Nairobi, Kenya, 2017.

25. Grimm, M.; Jones, R.; Montanarella, L. Soil Erosion Risk in Europe; Europen Comission Joint Research Center: Ispra, Italy, 2002.

26. Kirkby, M.; Irvine, B.; Jones, R.J.; Govers, G. The PESERA coarse scale erosion model for Europe. I.-model rationale and implementation. Eur. J. Soil Sci. 2008, 59, 1293-1306. [CrossRef]

27. Morgan, R.; Quinton, J.; Smith, R.; Govers, G.; Poesen, J.; Auerswald, K.; Chisci, G.; Torri, D.; Styczen, M. The European soil erosion model (EUROSEM): A dynamic approach for predicting sediment transport from fields and small catchments. Earth Surf. Process. Landf. 1998, 23, 527-544. [CrossRef]

28. Panagos, P.; Meusburger, K.; Van Liedekerke, M.; Alewell, C.; Hiederer, R.; Montanarella, L. Assessing soil erosion in Europe based on data collected through a European network. Soil Sci. Plant Nutr. 2014, 60, 15-29. [CrossRef]

29. Panagos, P.; Borrelli, P.; Poesen, J.; Ballabio, C.; Lugato, E.; Meusburger, K.; Montanarella, L.; Alewell, C. The new assessment of soil loss by water erosion in Europe. Environ. Sci. Policy 2015, 54, 438-447. [CrossRef]

30. Karamage, F.; Zhang, C.; Ndayisaba, F.; Shao, H.; Kayiranga, A.; Fang, X.; Nahayo, L.; Muhire Nyesheja, E.; Tian, G. Extent of cropland and related soil erosion risk in rwanda. Sustainability 2016, 8, 609. [CrossRef]

31. Nearing, M.A.; Xie, Y.; Liu, B.; Ye, Y. Natural and anthropogenic rates of soil erosion. Int. Soil Water Conserv. Res. 2017, 5, 77-84. [CrossRef]

32. Guo, S.Y.; Liu, B.Y.; Li, Z.G.; Zhou, X.Y.; Liu, S.Z. Soil Erosion Investigation and Asssessment; China Water\&Power Press: Beijing, China, 2014. (in Chinese)

33. Thomas, A. The onset of the rainy season in Yunnan Province, PR China and its significance for agricultural operations. Int. J. Biometeorol. 1993, 37, 170-176. [CrossRef]

34. Barton, A.; Fullen, M.; Mitchell, D.; Hocking, T.; Liu, L.; Bo, Z.W.; Zheng, Y.; Xia, Z.Y. Effects of soil conservation measures on erosion rates and crop productivity on subtropical ultisols in Yunnan Province, China. Agric. Ecosyst. Environ. 2004, 104, 343-357. [CrossRef]

35. Yang, Y.; Tian, K.; Hao, J.; Pei, S.; Yang, Y. Biodiversity and biodiversity conservation in Yunnan, China. Biodivers. Conserv. 2004, 13, 813-826. [CrossRef]

36. Zhang, Z.; Wang, X.; Zhao, X.; Liu, B.; Yi, L.; Zuo, L.; Wen, Q.; Liu, F.; Xu, J.; Hu, S. A 2010 update of national land use/cover database of China at 1: 100000 scale using medium spatial resolution satellite images. Remote Sens. Environment 2014, 149, 142-154. [CrossRef]

37. Liu, B.; Zhang, K.; Xie, Y. An empirical soil loss equation. In Proceedings of the 12th International Soil Conservation Organization Conference; Tsinghua University Press: Beijing, China, 2002; Volume III, p. 15.

38. Xie, Y.; Yin, S.Q.; Liu, B.Y.; Nearing, M.A.; Zhao, Y. Models for estimating daily rainfall erosivity in China. J. Hydrol. 2016, 535, 547-558. [CrossRef]

39. Duan, X.; Gu, Z.; Li, Y.; Xu, H. The spatiotemporal patterns of rainfall erosivity in Yunnan Province, southwest China: An analysis of empirical orthogonal functions. Glob. Planet. Chang. 2016, 144, 82-93. [CrossRef]

40. Yin, S.; Zhang, W.; Xie, Y.; Liu, S.; Liu, F. Spatial distribution of rainfall erosivity in China based on a dense meteorological stations network. Sci. Soil Water Conserv. 2013, 10, 45-51. (in Chinese).

41. Bryan, R.B. The development, use and efficiency of indices of soil erodibility. Geoderma 1968, 2, 5-26. [CrossRef]

42. Wang, B.; Zheng, F.; Römkens, M.J.; Darboux, F. Soil erodibility for water erosion: A perspective and Chinese experiences. Geomorphology 2013, 187, 1-10. [CrossRef]

43. Wischmeier, W.H.; Mannering, J. Relation of soil properties to its erodibility 1. Soil Sci. Soc. Am. J. 1969, 33, 131-137. [CrossRef] 
44. Fu, S.H.; Liu, B.Y.; Zhou, G.Y.; Sun, Z.X.; Zhu, X.L. Calculation tool of topographic factors. Sci. Soil Water Conserv. 2015, 13, 105-110. (in Chinese).

45. Hickey, R. Slope angle and slope length solutions for GIS. Cartography 2000, 29, 1-8. [CrossRef]

46. Foster, G.; Wischmeier, W. Evaluating irregular slopes for soil loss prediction. Trans. ASAE 1974, 17, 305-0309. [CrossRef]

47. Liu, B.; Nearing, M.A.; Risse, L. Slope gradient effects on soil loss for steep slopes. Trans. ASAE 1994, 37, 1835-1840. [CrossRef]

48. Zhen, L. The national census for soil erosion and dynamic analysis in China. Int. Soil Water Conserv. Res. 2013, 1, 12-18. [CrossRef]

49. Guo, Q.K.; Liu, B.Y.; Xie, Y.; Liu, Y.N.; Yin, S.Q. Estimation of usle crop and management factor values for crop rotation systems in China. J J. Integr. Agric. 2015, 14, 1877-1888. [CrossRef]

50. EBCCW. Book Series for the First National Water Census in China: Report for the Soil and Water Conservation Survey; China Water\&Power Press: Beijing, China, 2017. (in Chinese)

51. Panagos, P.; Borrelli, P.; Meusburger, K.; van der Zanden, E.H.; Poesen, J.; Alewell, C. Modelling the effect of support practices (P-factor) on the reduction of soil erosion by water at european scale. Environ. Sci. Policy 2015, 51, 23-34. [CrossRef]

52. Subedi, M.; Hocking, T.J.; Fullen, M.A.; McCrea, A.R.; Milne, E.; Mitchell, D.J.; Bo-Zhi, W. An evaluation of the introduction of modified cropping practices in Yunnan Province, China, using surveys of farmers' households. Agric. Sci. China 2009, 8, 188-202. [CrossRef]

53. Zisheng, Y.; Luohui, L.; Yunpeng, w. Analysis on main chracteristics of soil erosion in Jinsha River Basin of Yunnan. J. Mountain Sci. 2002, 20, 10-17. (in Chinese).

54. Zisheng, Y.; Luohui, L. Soil erosion under different land use types and zones of Jinsha River Basin in Yunnan Province, China. J. Mountain Sci. 2004, 1, 46-56. (in Chinese). [CrossRef]

55. Yang, Z.; He, Y. Soil erosion of cultivated land in mountainous areas at China's southwest border-a case study in Yunnan Province. Res. Soil Water Conserv. 2009, 16. (in Chinese). [CrossRef]

56. Uchida, E.; Xu, J.; Rozelle, S. Grain for green: Cost-effectiveness and sustainability of China's conservation set-aside program. Land Econ. 2005, 81, 247-264. [CrossRef]

57. Lei, D.; Shangguan, Z.; Rui, L. Effects of the grain-for-green program on soil erosion in China. Int. J. Sediment Res. 2012, 27, 120-127.

58. Yang, Z. The factor of soil and water conservation measures of soil erosion on sloping cultivated land in the northeast mountain region of Yunnan Province. J. Mountain Sci. 1999, 17, 22-23. (in Chinese).

59. Ndrc, M. The 13th five-year special construction plan for comprehensive management of soil and water loss in sloping farmland in China. Soil Water Conserv. China 2017, 4, 1-16. (in Chinese).

60. Tang, K.; Shi, L. Soil and Water Conservation in China; Science Press: Beijing, China, 2004. (in Chinese) 